\title{
Un ejemplo de transformación del pobla- miento rural durante la antigüedad tardía. La villa de "Morosanto" (Ronda, Málaga)
}

\author{
An example of transformation of rural settlement in late antiquity. The villa \\ of "Morosanto" (Ronda, Málaga)
}

José Manuel Castaño Aguilar *

\begin{abstract}
RESUMEN
En el presente trabajo se dan a conocer algunos de los datos aportados por la arqueología sobre las transformaciones experimentadas por un asentamiento romano caracterizado en su día como villa. De ellos, los que aquí se exponen son los relacionados con su evolución en el contexto del poblamiento tardoantiguo de la comarca de Ronda, lo que nos permite insertar este establecimiento en el debate sobre la desaparición de las villae y de las aristocracias ligadas a ellas.
\end{abstract}

Palabras clave: Arqueología, villa, AntigüedadTardía, transformación, poblamiento.

La intención de desarrollar un proyecto vitivinícola en la finca "Morosanto", cautelada desde el año 1993 desde el punto de vista patrimonial por la existencia de un yacimiento arqueológico de cronología romana, y la previsible realización de movimientos de tierras como consecuencia de la plantación de viñedos, motivó la puesta en marcha de un proyecto de intervención arqueológica que permitiera determinar con mayor exactitud la extensión

\begin{abstract}
In the present study disclosed some of the data provided by archeology on the changes experienced by a Roman settlement at the time characterized as a villa. Of these, presented here are those related to its evolution in the context of late antiquity settlement of the Ronda region, allowing us to set this property in the debate on the disappearance of the villae and aristocracies are attached to them.
\end{abstract}

Key words: Archaeology, villa, Late Antiquity, transformation, settlement.

y entidad del asentamiento, que ya suponíamos considerable por las características de sus restos en superficie. Para ello se realizó una prospección geofísica que condicionó el programa de intervención, concretado finalmente en una excavación arqueológica de varios sondeos repartidos por los sectores con mayor concentración de materiales en superficie y mayor detección de anomalías geofísicas ' (Lám. I).

\footnotetext{
* Museo de Ronda.

I. La intervención arqueológica realizada entre los años 2007 y 2008 bajo la dirección de Bartolomé Nieto, contó con la participación en el equipo técnico de los arqueólogos Jorge Padial y Raúl Hoyos, además de quien suscribe. Desde aquí mi agradecimiento por permitirme utilizar los datos aún inéditos para la redacción de este artículo; agradecimiento que quisiera hacer extensivo a los profesores Andrés M. Adroher y Manuel Acién, por sus correcciones y sugerencias al texto. En cuanto al estudio geofísico titulado "Prospección geofísica en el entorno del Cortijo de Morosanto", fue realizado por el Área de Prospección Geofísica del Instituto Andaluz de Geofísica (Universidad de Granada), bajo la dirección del Dr. José Peña, en noviembre de 2006.

Sobre dicho estudio cabe aclarar que no se planteó como parte de la estrategia de la investigación sino que, al contrario, sufragado por la propiedad, su finalidad era la de acotar de manera más exacta la localización de los restos para plantear los sondeos y poder valorar el alcance y grado de conservación de los mismos, que fue la razón de esta intervención preventiva.
} 


\section{SITUACIÓN (Fig. I)}

El cortijo de Morosanto se localiza en la cabecera de la cuenca del río Guadalcobacín, en la pedanía de La Cimada (término municipal de Ronda, provincia de Málaga), a los pies de la Sierra de las Cumbres, y muy próximo al cerro de las Salinas (Fig.2); lugar en el que se asienta uno de los yacimientos más característicos del poblamiento ibérico de la zona, y centro de actividades minerometalúrgicas y de explotación de salinas de histórica tradición ${ }^{2}$ (Fig. 3).

El valle del Guadalcobacín, antesala de lo que kilómetros más abajo será el valle del río Guadiaro del que es afluente, es un sinclinal de amplia concavidad, lo que ha determinado su conformación como valle abierto sobre fondos marinos netamente diferenciado del angosto trazado que describirá el anterior a partir de la Cueva del Gato. Esta cualidad, a la que se debe añadir una también generosa red de fuentes de agua, ha convertido este valle, quizá, en el más fértil de toda la depresión natural, desarrollándose en él un sistema de irrigación para una agricultura intensiva que llegó a ser conocido con el nombre de "huertas de Ronda" (huertas del Guadalcobacín, Ribera de los Frailes, huertas de Arriate), por ser de aquí de donde procedían una parte importante de los productos hortofrutícolas que se consumían en la comarca ${ }^{3}$.

Estas características, unidas a las particulares posibilidades de acceso a recursos geológicos como el hierro y la sal que ofrece el citado cerro de las Salinas, sobre cuya explotación son más que evidentes las huellas dejadas en el terreno, y la cercanía de un nacimiento de agua dulce (pues el arroyo que discurre junto al lugar es salobre), confirieron al emplazamiento de los condicionantes que habrán de pautar su existencia: la minería y una agricultura en la que el regadío deberá estar, por fuerza, presente.
Es por ello por lo que en el contexto del poblamiento romano, muy bien y densamente representado en todo el valle del Guadalcobacín desde época altoimperial, este asentamiento, aparte de ser el primero de toda la serie que jalona ambas riberas del río, constituye una buena posibilidad para estudiar la génesis y desarrollo de estas instalaciones rurales, y para apreciar una serie de cuestiones cuyo alcance y repercusión van más allá de su tradicional vinculación con lo estrictamente rural.

\section{CONTEXTO E HIPÓTESIS DE PARTIDA}

El asentamiento constatado en "Morosanto" se puede englobar en el amplio concepto de "establecimiento rural", definición que en el mundo romano hispano tuvo a la villa como elemento más representativo de su modelo de poblamiento; razón por la cual se suele atribuir esta categoría a los yacimientos de cronología romana documentados en superficie.

Se localiza en el fértil valle del Guadalcobacín, donde existen varios ejemplos de este modelo, y en el marco del ager de Arunda (Ronda). Por los restos superficiales documentados (mármoles, sillares, piedras de molino, fustes de columnas, teselas, fragmentos de opus signinum y abundante material cerámico, etc.) se presumió la existencia de una pars urbana y residencial, y de una pars rustica o fructuaria que abarcaría una amplia cronología.

En los más de $240 \mathrm{~km}^{2}$ de terreno prospectado correspondientes a la meseta de Ronda (última de las depresiones que jalonan el llamado "surco intrabético"), hemos podido constatar, de momento, alrededor de II 5 asentamientos romanos rurales de época alto imperial (segunda mitad del siglo I d. C.,

\footnotetext{
2. Sobre el yacimiento ibérico, calificado como atalaya dependiente de los oppida de Silla del Moro y Ronda (CARRILERO MILLÁN, 1992: pp, I 17-142) y (CARRILERO MILLÁN, 2006: pp. 62-77). Sobre las salinas y su explotación, (MADOZ, 1986: p. 198).

3. Sobre la importancia relativa de las superficies de regadío de la depresión de Ronda, restringida prácticamente a los valles de los ríos (RODRÍGUEZ MARTíNEZ, 1977: pp. 297-309) y (V.AA., 1994: pp. 239-253). Cabe apuntar que dicha incidencia resulta aún mayor si se considera que sólo el 5\% del total de la tierra cultivable de la Serranía es de regadío. De la fertilidad de las huertas de estos valles se hacen eco, incluso, los viajeros románticos de los siglos XVIII y XIX, como el inglés Francis Carter, Viaje de Gibraltar a Málaga (1777), Málaga, 198I.
} 
comienzos del siglo III d. C.). De esta extensión podemos decir que más de la mitad la forman tierras no aptas para el cultivo intensivo, aunque sí para otro tipo de explotaciones o aprovechamientos (caza, madera, minería, etc.), al estar constituidas por montañas, bosques de encinas y monte bajo y matorral (NIETO GONZÁLEZ, 1994: pp. 214-242). En el caso que nos ocupa, el yacimiento se localiza en un ámbito de oasis agrícola de claro potencial productivo con capacidad de generar excedente y en el contacto, además, con el bosque (silva-saltus) (Fig. 4).

El hallazgo en superficie de piedras de molino, aras de caliza y elementos afines, sugieren una producción centrada en el cultivo de la clásica tríada mediterránea, en la que, tal vez en nuestra zona, cobrara mayor relevancia la vid y el cereal, según se desprende de la iconografía empleada en las amonedaciones de la ceca de Acinipo, con su característico racimo trilobulado y topónimo o ceca entre espigas (MORA SERRANO, 1987-88. MORA SERRANO, 1990. MORA SERRANO, 2000). Sin embargo, esto no excluye la existencia de una agricultura mucho más diversificada y más difícil de distinguir en un registro arqueológico de superficie que incorporaría otros cultivos, como las huertas en las zonas bajas de los valles complementados con ganadería, elementos todos ellos tradicionales en la economía de la comarca.

Por la amplia extensión que abarcaba la dispersión de materiales, próxima a los 10.000 $\mathrm{m}^{2}$, y la variedad y riqueza de la cultura material que se visualizaba en superficie, Morosanto podría responder al modelo de villa esclavista que conocemos para la Bética, reproduciendo la compleja organización espacial y productiva de estos centros. En el área de la depresión tenemos 6 yacimientos que se localizan en un radio de $2-4 \mathrm{~km}$. de distancia de la ciudad de Acinipo y Arunda. La proporción de este tipo de estructuras, que podríamos valorar como esclavista, es minoritaria en relación a las 98 unidades de explotación familiar (pequeña y mediana propiedad) que hallamos en la zona al mismo tiempo (CARRILERO et al., 1995: pp. 89-108).
Los autores de este artículo (principalmente Carrilero y Nieto), artífices igualmente del modelo que seguimos (único planteado para esta época en nuestra zona), interpretan este proceso como una consecuencia de la concesión del "lus Latii" de Vespasiano a las provincias hispanas, lo que supuso en nuestra área de estudio la inclusión en el derecho latino de las ciudades de Acinipo, Arunda, Lacilbula y Sabora.

Por todo ello, suponían que hubo de haber asignaciones de tierras dentro del territorio de los municipios flavios de la depresión natural de Ronda, pudiendo deberse a ello, tal vez, la implantación rural que hemos descrito en la zona y en la que es más que probable la existencia de parcelaciones de este periodo en las tierras más productivas de la serranía. Estas parcelaciones y distribuciones de tierras componen la piedra angular sobre la que se articula el sistema de explotación de la villa, que sin duda, definirá un nuevo paisaje agroforestal en la depresión.

Este sistema de régimen de la propiedad dividida parece ir cambiando a partir de finales del siglo II d.C.y comienzos del siglo III d.C., con mayor incidencia desde éste último, dándose un desarrollo espectacular de algunas villae, así como una sensible reducción de su número, lo que implica un cambio en las relaciones de producción que se verá reflejado, por ejemplo, en la transformación, que no crisis, que experimentan los dos centros urbanos documentados: Acinipo y Arunda.

\section{EL YACIMIENTO}

La intervención llevada a cabo sobre el yacimiento ha permitido desvelar, aunque de una forma fragmentaria, algunos de los sectores con los que contó el asentamiento romano a lo largo de su dilatada existencia. La representación material de estos sectores, abundantes en estructuras de habitación de variada naturaleza, deja clara la importancia del lugar del que, a raíz de esta intervención, estamos convencidos de conocer sólo una mínima parte. Sin embargo, 
bien por las características de su situación, bien por las circunstancias de su evolución posterior, apenas si existe una secuencia suficiente que permita relacionar los diferentes acontecimientos que fueron consecutivamente transformando la faz del asentamiento original más allá, claro está, de aquélla que nos ha posibilitado poner fecha a algunas de estas operaciones, así como las que se relacionan claramente con su abandono.

Lo que conocemos de este sitio, como propuesta y para su mejor comprensión, invita a distinguir en él dos sectores "funcionales": el primero, que agrupa a los sondeos I, II, IV y VII, parece estar asociado, en su concepción inicial, con aspectos residenciales del asentamiento; con instalaciones vinculadas, tal vez, con el ocio y disfrute de sus propietarios. Mientras que el segundo, representado en exclusiva por el sondeo $\mathrm{V}$, trasluce una serie de infraestructuras de clara naturaleza productiva. Por último podríamos añadir un tercer sector, no asociado espacialmente, relacionado con el almacenamiento y distribución de agua, y caracterizado por dos grandes depósitos situados en los extremos noroeste y sureste del yacimiento (sondeos IX y III, respectivamente) (Fig. 5).

El sector que denominamos "residencial" está definido por dos áreas diferenciadas respecto a su uso final. Los sondeos I y II (Figs. 6 y 7), desvelan una misma infraestructura de grandes proporciones relacionada con la contención de agua que interpretamos como natatio, a la que se asocia, también con fines balnearios, la pequeña terma documentada en el sondeo IV (Fig. 8). Esta natatio, con revestimientos de opus signinum en suelo y paredes, pudo haber estado relacionada con las habitaciones localizadas en el sondeo VII, cerrándose hacia el sur con un muro de sillares y contrafuertes que, aparte de constituir el límite de la terraza en la que se asienta, serviría asimismo de cierre de la edificación allí existente. Las habitaciones mencionadas, concretamente dos estancias, se desarrollaban hacia el sur sobre otra terraza generada por encima de la anterior (de la natatio), y contaban con la particularidad de utilizar como límite nororeste el mismo muro de contención sobre el que posteriormente se edifica- rá el cortijo moderno, lo que ha permitido, en este tramo no afectado por las habitaciones de la vivienda rural, conservar intacto parte de los revestimientos policromados contemporáneos a la villa (Fig. 9, MR68504).

Por su parte, el balneum del sondeo IV, aparentemente algo alejado de los sondeos anteriores si no consideramos que el vacío existente es producto del derribo del cortijo, que según se ha visto, fue construido sobre algunas de las estancias de la misma villa, se definió por la documentación de parte de lo que fuera el hipocausto (y por ello, del caldarium), evidenciado por el sistema de pilae que sustentaba la suspensura, que será en nuestro caso la que marque la cota máxima de los restos conservados de esta instalación.

Sin embargo, a la luz de la estratigrafía esta zona residencial mostrará una evolución diferencial de cada uno de los elementos que la conforman, lo que supondrá en unos casos una modificación funcional, y en otros simplemente su desaparición. El ejemplo más evidente de lo primero puede apreciarse en los sondeos I, II y VII. La natatio presenta huellas de un cambio de uso después de ser desmantelada en gran medida, lo que queda de manifiesto en la apertura de hoyos de poste en el suelo de signinum, y en la construcción de un pilar central, indicios ambos de un cambio en su sistema de cubierta. A ello habría que unir la escasez de restos de materiales constructivos propios de techumbres que contenía el único relleno que la amortizaba (US6804, bastante homogéneo y de considerable grosor), y por el contrario la abundancia de otros materiales, como las cerámicas, entre las que sobresalen las ARSC o los restos de vasijas de almacenaje. Es un análisis de las sigillatas el que permite establecer el final del siglo III y los inicios del IV d.C. como punto de inflexión de la instalación, que de lugar subsidiario a labores productivas (quizá como almacén), pasa a convertirse en vertedero.Y, además, parece que de una manera precipitada. El elevado número de ejemplares de ARSC de los tipos Hayes 51 y 53B (datados en el siglo IV y primeros años del $V$ ) invita a pensar que su relleno debió comenzar a producirse, al menos, a partir de estas fechas. 
En el sondeo VII pasa algo parecido, sólo que un siglo más tarde. Como en la natatio, no se alterará sustancialmente su estructura original, pero probablemente sí se desmantelarían los pavimentos de sus estancias, de los que no hemos encontrado ni sus huellas, lo que no ocurre, por ejemplo, con algunos de los revestimientos originales, conservados aún en sus muros. Los rellenos parecen delatar un cambio en la funcionalidad de estos espacios que de estar dedicados a tareas acordes con los ambientes en los que la decoración parietal juega un papel estético, esto es, más relacionados con ámbitos domésticos, pasarán a convertirse en lugares de almacén, en los que son habituales los grandes contenedores cerámicos y, tal vez por ello, la ausencia de suelos. De uno de estos estratos (US 68.502, de la habitación E/II) proceden algunos ejemplares de ARSD del tipo Hayes 9IA, datados en la segunda mitad del siglo $\vee$ d.C., que se entremezclaban con cerámicas comunes de cocina realizadas a mano/torneta y con numerosos fragmentos de estucos pintados procedentes de las paredes de la habitación, y que en un alto porcentaje se encontraron presentando concordancia entre sí.

Otro espacio cuya funcionalidad cambia de forma radical es el balneum del sondeo IV; la ausencia de cerámicas tardías nos hace pensar que estuvo en funcionamiento hasta el siglo II d.C., pues encontramos formas como TSHisp 72, y africanas de cocina forma Ostia II, 306. A partir de cierto momento, en esta estancia se detectan actividades de expolio de material de construcción, posiblemente para ser empleado en las reformas que se están llevando a cabo en otros puntos de la casa, lo que nos lleva a pensar que el balneum ha sido amortizado con anterioridad, y, en consecuencia, habría que fechar dicho abandono hacia el siglo III d.C.

El sector de la excavación que podríamos denominar "productivo" se concentra en el sondeo $\vee$ (Fig. I0). Lo más relevante en él fue la documentación de una serie de estancias e infraestructuras con una clara filiación productiva relacionada probablemente con la transformación de vino o aceite. Esta es la conclusión que sacamos a raíz de la aparición de elementos de prensa (ara UC68359), pilas de contención de líquidos revestidas de opus signinum con los típicos baquetones de limpieza $\bigcirc$ cuartos de bocel (estancias E/3 $\circ$ E/4), algunas interconectadas (PT686I0), restos de grandes vasijas de almacenamiento (como las halladas in situ en la estancia E/IA), etc.; así como otras infraestructuras vinculadas a procesos concretos en el marco de esas labores (hipocausto, estancia E/5), que podrían implicar la introducción de nuevas técnicas, o espacios de tránsito y comunicación entre terrazas, como escaleras (UC68348) o pasillos, o simplemente abiertos. Terrazas constructivas tenemos dos en el sondeo; una al norte de las escaleras (y del muro a las que se adosan éstas), y otra al sur. El taller se situaría en la norte.

En todo el conjunto se aprecian diferentes fases tanto en lo general (producto de una reforma del sitio), como en lo tocante a las propias estructuras, aunque sobre estas operaciones no podamos más que avanzar los momentos en los que se obliteran, correspondientes con los grandes paquetes de amortización excavados en todo el sondeo ${ }^{4}$. Si nos acercamos a ellos se puede advertir cómo la amortización tal vez más fiable que hemos observado podría datarse en el siglo IV d.C., a tenor de las cerámicas contenidas en el nivel depositado sobre el suelo de signinum de la estancia E/3 (Hayes 87A y 99B, de la segunda mitad del siglo $\vee$ y del siglo $\mathrm{VI}$, respectivamente), además de algunos ejemplares procedentes del contacto con el empedrado de la estancia E/7A, datadas hacia mediados del VI d.C. (ARSD Hayes $9 / C)$. El resto de los rellenos arqueológicos del sector comienzan a producirse hacia la segunda mitad del siglo $\vee$ d.C. (al igual que ocurría en el sondeo VII), como son los casos de los niveles que obliteran el hipocausto (itabulatum?), con

\footnotetext{
4. Somos conscientes de que sólo presentamos momentos de amortización y/o abandono, pero hay que decir que la inmensa mayoría de los niveles excavados comparten esta característica. No obstante esto mismo es ya en sí bastante ilustrativo del devenir en el que se ha movido el asentamiento.
} 
cerámicas que van desde la segunda mitad del siglo IV (H67), a la primera mitad delV (H6|B) y, además de las sigillatas, algunos ejemplos de cerámicas elaboradas a mano/torneta. $\bigcirc$ las estructuras situadas al sur de la escalinata, para las que en ningún caso hemos hallado evidencias cerámicas anteriores al siglo IV y sí, por el contrario, más cercanas al $\mathrm{V}(\mathrm{H} 67,87 \mathrm{~A}$ ○ 91), algo, por lo demás, recurrente en todo este sector.

Por último quedaría tratar los dos depósitos de agua localizados en los extremos del yacimiento. En el caso del más alto (sondeo $I X)$, para el que no tenemos materiales de referencia (posiblemente por su uso continuado y posterior desmantelamiento), podría tratarse de un castellum aquae que suministraría agua a gran parte de la villa, tomándola a su vez de una fuente cercana de agua dulce (el arroyo que discurre por el oeste es salobre, como se ha dicho). Se encontraba revestido de opus signinum y contaba con una superficie de unos $70 \mathrm{~m}^{2}$. Por su parte, el depósito del sondeo III sí ofrece una historia interna más interesante (Fig. I I). Localizado al sur de la natatio y, por tanto, del sector que consideramos residencial, sus revestimientos y las dimensiones que dibujaba invitaban a incluirlo como infraestructura vinculada al agua. Al mismo tiempo su situación sugería unos usos diferentes de los vistos hasta el momento, toda vez que, por debajo de él, no se habían encontrado indicios de ocupación. Es por ello por lo que suponemos para este caso un uso centrado en el regadío agrícola. Pero como decimos, en él sí se han detectado operaciones que terminaron por anularlo, aunque parte de su solar fuera utilizado, tiempo después, para algún tipo de construcción que no guardaba ya con él ninguna relación.

Entre los materiales recuperados en los rellenos de este sondeo se encuentra un grupo representativo de $A R S D$, contenidas en un relleno de amortización bastante homogéneo (US68 I06) que, en cierta medida, recordaba al descrito en el caso de la natatio. La cronología que arrojan estas cerámicas puede situarse entre los siglos IV y $\vee$ d.C. (Hayes 6 I y 67), con algún caso introducido en el siglo $\mathrm{VI}(\mathrm{H} 9 \mid \mathrm{C})$, centuria a la que debería pertenecer una construcción de no muy buena calidad situada sobre la cisterna y sus rellenos.

A la luz de lo expuesto surgen una serie de cuestiones relativas a la fundación de la villa y a su evolución espacial y funcional. Tras revisar la cerámica, lo primero que llama la atención es la ausencia de materiales altoimperiales en los rellenos arqueológicos, que sin embargo, sí estaban presentes en superficie cuando se detectó el asentamiento en prospección. Los pocos que hemos encontrado se localizan en la terma, y lo único que permitirían avanzar es la probable fundación del establecimiento en época flavia.

En segundo lugar es llamativa la homogeneidad de los paquetes que amortizan las estructuras y los diferentes espacios, algunos con un grosor considerable, lo que da muestras de las grandes remociones que se operaron como producto de importantes reformas en algunos sectores de la villa.

La primera de ellas, que tiene como escenario principal (al menos más evidente) el área sureste del yacimiento (los sondeos I, II, III y tal vez también el IV, aunque que este último utilizado sólo como cantera de material de construcción), no rebasaría el siglo $\vee$ d.C., pudiéndose establecer el inicio de su amortización a partir de mediados del siglo IV. Por tanto, las refacciones observadas en el sondeo II, consistentes en la apertura de hoyos de poste y construcción de un pilar central, debieron realizarse con anterioridad a lo expresado; quizá entre finales del siglo III y la primera mitad del IV d.C.

La segunda gran reforma se concentra en los sondeos $\mathrm{V}$ y VIII, si bien cabe advertir algunas diferencias entre ambos. En los dos aparece el siglo $\vee$ d.C. como el momento en el que se reestructuran ciertos espacios (momento, en general, en el que se amortizan los ya citados), aunque no en fechas coincidentes: en el caso del sondeo VII, su terminus ante quem podría fijarse en la segunda mitad del siglo $V$, mientras que en el sondeo $V$ algunas de sus estancias se colapsarán a partir de la segunda mitad de esa centuria, determinando un terminus post quem 
de todas estas amortizaciones para el resto del sondeo en la primera mitad del siglo VI d.C. Esto mismo indicaría el inicio del abandono total del asentamiento hacia la mitad de este mismo siglo.

De forma esquemática, nuestra propuesta evolutiva de la villa seguiría las siguientes fases:

I. Fundación (siglos I-II d.C.)

2. Primeras reformas (siglos III y IV d.C. - sondeos | y ||$-$ )

3. Segundas reformas (siglos $I V y \vee$ d.C. - sondeos $\vee$ y $\vee I-$ ) y primeras amortizaciones (siglos IV y V d.C. - sondeos I, II, III y IV-)

4. Segundas amortizaciones (siglos $\vee-V I$ d.C. -sondeos $\vee$ y $\vee \mathrm{II}-$ )

5. Abandono (siglo VI d.C.)

\section{Necrópolis}

Por último, y por encima del sondeo IX se descubrieron los restos de unas inhumaciones de época medieval, de las que han sido localizadas cuatro sepulturas, orientadas al sureste, del tipo de fosa simple con cubierta de lajas de piedra y con cadáver en decúbito lateral.

Esta necrópolis no está asociada, por el momento, a ningún asentamiento próximo conocido arqueológicamente. En el caso que nos ocupa, y aunque contamos con el topónimo, no tenemos desgraciadamente elementos materiales que permitan advertir la existencia de una alquería, al menos sobre el yacimiento romano excavado. Sin embargo, la tipología de las sepulturas y la disposición de los cadáveres reflejan con claridad el empleo del ritual funerario islámico.

\section{INTERPRETACIÓN}

La primera sensación que se advierte a nivel general tras la intervención, y que afecta prácticamente a casi todos los sectores excavados, es la imponente transformación que debió sufrir la villa en sus últimos momentos de existencia, y al mismo tiempo, el continuado uso de determinados espacios (que no necesariamente de funciones) y estructuras, lo que ha impedido y dificultado bastante la visión de algunas fases del yacimiento.

Como se ha visto, se han distinguido tres sectores en el yacimiento a los que, a continuación, atribuiremos cuatro ámbitos según su función:

a. Un ámbito doméstico al que se corresponden los sondeos I, II y VII, representado por estructuras y espacios que, aún siendo reutilizados con posterioridad para albergar contenedores de almacenaje, presentaban un cierto cuidado en el tratamiento de algunos de sus paramentos, revestidos de estucos pintados. Junto a estas estancias, aunque en un nivel más bajo, se sitúa una gran piscina con una longitud aproximada de 20 metros, una anchura de 6 y un alzado conservado de más de medio metro, con escaleras de abanico en los ángulos (al menos en los dos excavados), que contaba con un gran muro de opus africanum como cierre oriental.

b. Un ámbito termal (sondeo IV), que podría incluirse en el anterior, pero que consideramos de forma aislada por no contar con relaciones estructurales directas entre ambos. El grado de destrucción es importante, pues no se han conservado alzados, ni hemos hallado evidencias que apunten hacia su reutilización o cambio de uso posterior.

c. Un ámbito productivo agrícola, representado por un depósito cuadrangular (sondeo III) de grandes proporciones, que se sitúa en lo que consideramos periferia de la zona edificada, en el área más suave de la pendiente, y que probablemente estuviera destinado al cultivo de regadío.

d. Y por último, un ámbito productivo artesanal/ industrial, localizado en el sondeo $V$, en el que se han descubierto sucesivas instalaciones o restos de infraestructuras relacionadas principalmente con la transformación de 
vino o aceite, localizadas, casi con toda probabilidad, sobre fases precedentes y usos, tal vez, diferentes.

El depósito que falta daría servicio al conjunto de la villa, por lo que no lo incluimos en ningún ámbito concreto.

\section{El ámbito doméstico y las termas}

Desgraciadamente el cortijo derribado debió ocupar una parte considerable de la zona urbana de la villa, lo que ha resultado bastante negativo para la conservación de su registro. Dada su situación en ladera, las labores previas a la edificación de este cortijo de finales del siglo XVIII supusieron el vaciado de los niveles arqueológicos correspondientes a este sector del yacimiento romano; desmonte que, por su organización escalonada, fue total en el volumen residencial de la casa y parcial en el dedicado a las áreas de servicio, como las cuadras (donde se halla la natatio). Sin embargo, no todo fue destruido porque esa misma situación escalonada heredera del asentamiento romano, ha motivado el mantenimiento de las principales crujías registradas sobre el terreno en los muros de contención de las paratas preparadas para la construcción de la edificación romana.

Así, por ejemplo, al plantear el sondeo VII se pudo observar que el muro medianero oeste sobre el que descansaba la vivienda actual derruida, se prolongaba hacia el noreste bajo los primeros estratos superficiales, conservando, a partir de aquí, restos de los revestimientos policromados originales (Fig. 9, MR68504); o cómo se empleó el cierre occidental de la natatio como muro divisorio entre los sectores residencial y de servicios del cortijo, que servirá asimismo de estructura de contención entre terrazas en época romana (Lám. II). No obstante, el grado de conservación de este último ha imposibilitado el establecimiento de relaciones espaciales entre ambas terrazas de origen romano, si bien su interconexión debió ser más que segura.

La situación de los elementos hallados (de las estancias) permite formular, sin embargo, una hipótesis sobre la organización de la pars urbana de la villa. Habida cuenta que las dos estancias que consideramos de carácter doméstico se localizan en una terraza superior a la gran piscina (sondeo VII), y que avanzando a favor de la ladera se encuentra un depósito de agua que suponemos para fines agrícolas, el cuerpo residencial del asentamiento romano tuvo que ocupar parte o la totalidad del que tuviera el cortijo, así como desarrollarse hacia el oeste y el norte del mismo. $\bigcirc$ lo que es igual, ocupando una posición central, entre dos áreas destinadas a la producción: una artesanal o de transformación (por encima), y otra agrícola (por debajo) ${ }^{5}$.

En el mismo sector incluimos los restos de lo que pudo ser parte del área calefactada de un balneum. Es frecuente que este tipo de asentamientos rurales contasen con baño doméstico, por lo general, cercano o unido a la parte urbana de la villa. Sobre las características del nuestro bien poco podemos decir. Su nivel de destrucción, que ha supuesto la total desaparición de los alzados, y el mal estado de conservación por haber sido objeto de los empujes y arrastres de la ladera, así como la adaptación de ésta para la consecución de terrazas de cultivo (huertas), han provocado la falta de niveles de uso asociados, así como la práctica ausencia de materiales que permitan como mínimo una datación aproximada o una propuesta de desarrollo.

Sólo la conservación de algún elemento estructural de la terma, como es su sistema de

\footnotetext{
5. Piscinas de características parecidas y localizadas junto a la parte residencial de la villa, las encontramos en grandes villae bajoimperiales y tardoantiguas como las de Sao Cucufate (en la que se documentan dos, una de ellas exenta de la pars urbana), al sur de Portugal, el ejemplo quizá más representativo por sus dimensiones; la de Els Munts, en el territorio de Tarraco (CHAVARRÍA ARNAU, 200 I: pp. 69 y 73), o, ya en el ámbito más inmediato de la provincia de Málaga, las "albercas" de la villa de las Torres de Estepota (FORNELL MUÑOZ, 2005: p. 704, fig. 31);del Sol, en Fuengirola (PUERTAS, I 989), o la natatio de las termas de la villa del faro de Torrox (FORNELL MUÑOZ, 2005: p. 716, fig. 43).
} 
hipocausto con pilares de ladrillo sin arcos de sustentación de la suspensura, y los fragmentos de tubuli que se encuentran dispersos en distintos rellenos del yacimiento, incluido los excavados en las termas (junto a las cerámicas ya comentadas), podrían ser utilizados para avanzar una fecha relativa de inicio que rondaría la segunda mitad del siglo I d. C. La ausencia de trazas de monumentalización en el baño, tan frecuentes (o al menos no extrañas) en las villae a partir del siglo III, y sobre todo en los siguientes ( $\mathrm{V} \mathrm{y} \mathrm{V}$ ), ofrece, sin embargo, una probable fecha para su final; fecha que, además, podría verse reforzada por los materiales que conformaban el relleno de amortización de la natatio, entre los que se encuentran ARSD y ánforas tardías datadas hacia la segunda mitad del siglo IV d.C., mezclados con otros de carácter constructivo que delatan el probable empleo de esta infraestructura como vertedero.

Parece pues que nuestra villa, que tuvo una pervivencia considerable, no fue, sin embargo, objeto de remozado por parte de su propietario. Es aquí donde la norma aplicada a la mayoría de instalaciones de este tipo que suelen presentar una perduración en su uso importante, en términos cronológicos rebasando el siglo $\mathrm{VI}$, se altera, pues no contamos con datos que permitan apreciar operaciones de engrandecimiento o "monumentalización" en Morosanto (algunos restos de materiales encontrados en superficie deben proceder de la villa altoimperial, como el empleo del aquí conocido como mármol rosa -en realidad brechas locales de una caliza nodulosa-, que documentamos en las termas de Acinipo en operaciones datadas en los siglos II-III, o utilizado para piezas de ornamentación, como pedestales); o, en el otro extremo, acciones de amortización de áreas domésticas para ser reutilizadas como instalaciones productivas, práctica que suele ser usual también en las mismas fechas.

Ello no implica necesariamente la omisión de uso de estos espacios "domésticos", pues tanto en la natatio, como hemos comentado, como en las estancias inmediatamente superiores, se han encontrado materiales tardíos que, sin embargo, no están presentes en la terma, aunque esta ausencia pueda deberse a procesos ulteriores que no han dejado huella en el registro.

Sobre las probables estancias de la parte urbana hay un dato que llama poderosamente la atención, aunque su constatación se extienda a otras partes de nuestro territorio, como en Ronda y Acinipo: la convivencia del tratamiento más o menos cuidado de los paramentos y el empleo, al parecer sistemático, de suelos de tierra. Esta práctica, que en los comienzos pudimos achacar al expolio de pavimentos, y que tradicionalmente se ha venido datando en la antigüedad tardía, resulta más usual de lo pensado también en momentos anteriores correspondientes al alto y bajo imperio. Tal es así, que en nuestro caso contamos con ejemplos de estos dos momentos, si bien ambos se dan también en ciudades: en Acinipo, con pavimentos de este tipo localizados en la domus datados entre los siglos I y || d. C. (CASTAÑO y NIETO, 2009: pp. 75- 100); y en Ronda, donde estos suelos se muestran amortizados por niveles de incendio fechados por un conjunto de monedas entre el siglo IV y mediados del $\mathrm{V}$, siendo por tanto contemporáneos a una conducción de agua potable del siglo III d. C. (AGUAYO; CASTAÑO y PADIAL, 2004: pp. 772-778).

En el caso de Morosanto, estos suelos, o mejor dicho, los niveles generados sobre ellos (pues de los pavimentos no nos ha quedado más señal que la dejada por la superficie establecida por estucos), aportan cerámicas bastante tardías (H-9l), lo que induce a pensar, como hipótesis de trabajo, que su uso prolongado no supuso alteraciones notables de su estructura original, aunque sí de su función, dada la presencia de grandes vasijas de almacenamiento. Sin embargo, tampoco debemos ser categóricos al respecto, pues el conocimiento que poseemos de este sector es bastante reducido, y la estratigrafía conservada sólo aporta una tenue luz sobre una determinada franja temporal correspondiente a los últimos momentos.

Lo cierto es que tanto las estancias "domésticas" apuntadas arriba, como la natatio, proporcionan evidencias de haber estado funcionando en épocas tardías, quizá también de forma com- 
plementaria y subsidiaria. De hecho, esta última infraestructura cuenta de momento (pues no ha sido excavada en su totalidad) con huellas de agujeros de poste abiertos en el pavimento de opus signinum, o un tosco basamento de mampostería sobre el suelo, para una función indeterminada anterior a su relleno que, como se ha comentado, debió ser coetánea a la fase tardía documentada en las estancias superiores, extensible también a otros sectores de la villa como el dedicado a labores productivas ${ }^{6}$.

\section{Los ambientes productivos}

\section{El ámbito agrícola}

Si aparte del topónimo, Morosanto, y de la necrópolis, contáramos con más elementos de contrastación, se podría decir que nos encontramos ante una alquería con un importante sistema de regadío. Pero lo que se desprende del registro y de la tipología de los elementos hallados es que todo el sistema empleado y generado en torno al agua es de indudable origen romano.

Como hemos comentado más arriba, en la excavación se sacaron a la luz un par de depósitos de grandes dimensiones, aparte de la natatio, cuya finalidad más que probable sería la de almacenar agua, que sería conducida con seguridad desde la cercana fuente de agua dulce. El primero de los depósitos se ubica allí donde debe estar, según el patrón seguido para este tipo de asentamientos rurales (y de los condicionantes físicos impuestos para este tipo de aprovechamientos acuáticos, en los que la gravedad es la única acción que se emplea para su funcionamiento); esto es, a cotas superiores que el resto de instalaciones que conformarían la villa, pues desde él el agua sería conducida hacia los distintos ambientes en los que este elemento fuera necesario (así, por ejemplo, las termas, los sectores domésticos y los productivos que emplearan agua para el desarrollo de la actividad). Pero, sin embargo, nuestra atención se centra en el segundo de los depósitos, de fábrica algo más ruda que el anterior y con semejanzas con la natatio, con la que comparte el mismo sistema de contrafuerte escalonado en los ángulos (escalera de abanico y cordón hidráulico, o cuarto de bocel).

Esta cisterna, probablemente abierta como la anterior (de hecho, no hemos encontrado indicios de cubierta en los rellenos), se ubica en el extremo opuesto, es decir, en la zona más baja y llana del pie de monte donde se instala el asentamiento. Sus considerables dimensiones, con más de siete metros de lado en sus caras internas y una profundidad estimada entre el metro y medio y los dos metros, que proporcionan una gran capacidad de almacenamiento, denotan que la finalidad para la que sirvió requirió un caudal suficiente y constante de agua. Esto, unido a su localización, invita a pensar que hubiera podido estar relacionada con el desarrollo de la agricultura de regadío. Esta propuesta, además, cobra mayor sentido por el lugar que ocupa el depósito, que le permitiría recibir los sobrantes de agua de las instalaciones vinculadas a ésta que se encuentran por encima, como son las termas y la propia natatio.

El regadío agrícola parece constatarse ya desde época ibérica ${ }^{7}$, y sabemos por los textos clásicos que existía en época romana un amplio conocimiento de la horticultura. Pero quizá porque ésta no participaba de

\footnotetext{
6. No sabemos si esta instalación llegó a tener, en alguna ocasión, cubierta, y de qué tipo. Pero los agujeros de poste sí que delatan que, al menos en el momento en que se abren, no existía la techumbre original, generándose, a través de ellos, una nueva cubierta, probablemente de tipo vegetal. No obstante en el interior también se ha hallado material constructivo propio de tejados, aunque no en suficiente cantidad y relativa cohesión como para considerarlo perteneciente a la última cubierta.

7. Aunque no podamos extrapolarlo a nuestra zona, por falta de investigación, sí existe documentación de calidad procedente de yacimientos ibéricos del Levante peninsular, en los que se han podido constatar sistemas de irrigación con el empleo de aljibes, como en el poblado de Covalta (Albaida, Valencia) o Elche, o el uso de herramientas exclusivas, podría decirse, de esta clase de agricultura, como el legón, hallado en poblados de la Edetania y Contestania (UROZ SÁEZ, 1999: pp. 59-85).
} 
los circuitos comerciales a escala imperial ${ }^{8}$, como ocurría con los productos de la tríada mediterránea (y porque no generaba grandes obras de infraestructuras, hallándose siempre en las áreas marginales de las villae), ha pasado casi inadvertida para los investigadores 9 . La verdad es que no son muy abundantes los ejemplos en la historiografía en los que se aborden problemas e hipótesis sobre este tipo de áreas productivas asociadas a las villae, ya que los análisis desarrollados en casi todas las investigaciones se centran sobre todo en el aparato constructivo, para de ahí establecer una jerarquización de espacios.

\section{El ámbito artesanal}

El sondeo $V$ es, con diferencia, el que mayor complejidad presenta, ya que la comunión entre conservación desigual de estructuras y espacios, y perduración temporal, ha provocado que llegue hasta nosotros una abigarrada lectura de dificultosa comprensión. Una cosa sí es clara: se tratan de espacios y elementos de carácter productivo que experimentaron continuas reformas, reutilizaciones y amortizaciones, algunas de ellas tan traumáticas que prácticamente han borrado toda posibilidad de establecer visiones sincrónicas entre las fases que lo componen. Por tanto, nos movemos en el terreno de lo diacrónico, en el que se mezclan fragmentos de fases precedentes sobre la que descansarán las evidencias de los últimos usos, amputadas, éstas también, por factores humanos y mecánicos.

Asimismo, también parece evidente que durante toda su existencia este sector de la villa estuvo dedicado a la producción, como reflejan los restos que, por el momento, consideramos de mayor antigüedad, consistentes en dos fragmentos de estructuras; un muro y un probable poyete paralelo a éste al que se adosan los fondos de un par de dolia, todos ellos arrasados por un posterior nivel de suelo (Lám. III) ${ }^{10}$. Desconocemos el contenido que hubieran podido tener las vasijas (las únicas halladas in situ en este sector), aunque seguramente fuera aceite $\mathrm{o}$ vino, de considerar cierta no sólo la continuidad en la función del sector, sino también las materias primas que se transformaron en él.

Ejemplo de esta transformación es el ara localizada (Lám. IV), vinculada a una serie de estructuras que permiten contemplar la que fuera segunda gran fase de transformación de este espacio: pavimentos de piedra, muros de paratas destinados a organizar el espacio urbanizado en la ladera, elementos de tránsito (como la escalera), depósitos intercomunicados, e incluso infraestructuras para la generación de calor, con características propias de los hipocaustos y para la que, de momento, no nos atrevemos adelantar una adscripción determinada (Lám. V) ${ }^{\prime \prime}$. En definitiva, todo un

8. Se tratan siempre de productos perecederos, por lo que su distribución no debe ser mayor que la escala local o comarcal.

9. El regadío agrícola cuenta con una amplia representación en los asentamientos rurales de época romana, si bien ejerciendo un papel secundario, como se aprecia en la campiña del Guadalquivir, lugar por excelencia relacionado con la producción a gran escala de cereal, olivo y vid, que le granjeó fama a la provincia Bética, donde, sin embargo, se documenta gran número de villae con infraestructuras destinadas a la irrigación, la cual, por otra parte, aunque de forma marginal, se aplicaba también a alguna especie de vid (vides capitatae) (LACORT, 1988: p. 75).

10. La instalación de estas grandes vasijas de almacenamiento, cuando no se hace con posterioridad rompiendo pisos precedentes, se suelen ubicar en estancias carentes de suelos o, más bien, terminadas con suelos de tierra (CARRILLO DÍAZ-PINÉS, I995: p. 6I5).

I I. Es una estancia que presenta, al menos, dos fases claras. Sobre su contemporaneidad con el ara, poco podemos avanzar, pues los vínculos estructurales con ella se encuentran solapados por elementos más recientes. El supuesto de sala calefactada viene de la mano de los pilares adosados con evidencia de arranques de arcos que se conservan y que solapan una fase anterior. No obstante, en la descriptiva empleada para numerosas villae destinadas a la producción de aceite (el Gallumbar (ROMERO, I993 y 1998 ) y Arastipi (PERDIGUERO, 1996) -Antequera, Málaga-; Fuente Grande (LAGÓSTENA y MATA, 2007) -Alcalá delValle, Cádiz-,Villaricos (AMANTE y LECHUGA, I99I) -Mula, Murcia-, etc.), se hace referencia a una estancia, contigua a la sala de prensa, llamada tabulatum, una suerte de troje, donde se almacenaría la aceituna antes de ser prensada, que contaba con un suelo inclinado que, en ocasiones, se sustentaba sobre pilares. La finalidad de esta habitación, de características variables, según se deduce de la bibliografía, era la de filtrar la amurca o alpechín generado por la maceración del fruto al almacenarse, debiendo ser eliminado para no dar amargor al producto final. En la fase en la que nos encontramos, esta función encajaría bien con el resto de los elementos hallados, aunque en nuestro caso no tengamos claro, de momento, el lugar que ocuparían las dependencias más características de este tipo de fábricas, como el torculatum o la cella olearia. No obstante, esta interpretación, según de observa en el contexto, se posiciona como la más plausible. 
programa constructivo en torno a la principal tarea productiva de debió desarrollarse en este lugar, y que, como decimos, tuvo que estar relacionada con el aceite o con el vino ${ }^{12}$.

Todo el conjunto experimentó a lo largo del tiempo reformas y refacciones, amortizaciones con rellenos y recrecidos de muros, que resultan difíciles de relacionar entre sí. No obstante, de ellas, la mejor documentada por suponer una de las reformas más integrales de todos los espacios previos, y probablemente la última, es la que dejó como testigos los dos pavimentos de opus signinum contiguos (estancias E/3 y E/4), de los que el más bajo (E/3) se instaló sobre el ara comentada. La trasformación del sector por causa de esta reforma fue casi total, teniendo como protagonista principal los aportes de rellenos intencionados seguramente para conseguir mayores superficies de uso, lo que supuso, a efectos prácticos, la eliminación de ámbitos espaciales en distintos planos. Desgraciadamente no se han conservado niveles de uso, salvo los correspondientes a los pavimentos de opus signinum que poco han aportado, pero los rellenos generados en esta operación sí albergaban materiales con posibilidades de datación, lo que nos ha permitido encuadrar esta fase entre los siglos $\mathrm{N} \vee$ y $\vee$ d. C., y tal vez algo del VI.

Pero aunque no podamos reflejar con mayor detalle en qué consistieron las reformas documentadas, y a qué época se corresponderían, al margen de que algunas de ellas aún están en discusión, lo que más nos llama la atención a efectos históricos es la cronología tan tardía que presenta la última fase y, más que esto, la falta de correspondencia observada en otros sectores excavados que, si bien estuvieron conviviendo (como ocurre con el doméstico), no fueron objeto de transformaciones importantes que alteraran lo previo y que dejaran huellas visibles en el registro. Las implicaciones históricas que ello conlleva nos parecen la aportación más interesante de esta excavación, aparte de lo que pueda resultar sobre la funcionalidad de los espacios documentados, únicos de estas características de los hallados en la comarca de Ronda, por el momento.

\section{CONCLUSIONES}

Morosanto es, pues, una villa de probable origen altoimperial y larga perduración que experimenta una importante transformación a partir del Bajo Imperio. Pero esta transformación no parece afectar de forma notoria a la parte urbana del asentamiento, como suele ocurrir de forma más generalizada en las instalaciones de este tipo que perviven más allá de los siglos III y IV d.C. En nuestro caso, la máxima atención se centrará en la parte rústica (fructuaria), concretamente en las zonas de ésta ligadas a la transformación de materias primas, vino o aceite, que además no se instala sobre ambientes domésticos previos, sino sobre ámbitos que ya habían gozado de ese mismo carácter con anterioridad. Esta circunstancia determinaría una cierta especialización productiva que se vería incentivada por los favorables atributos geográficos del lugar, lo que teniendo en cuenta el nuevo sistema de propiedad de la tierra, pudo provocar la elección de este asentamiento como una célula de producción perteneciente a un aristócrata que bien podría tener su residencia a varios kilómetros de ella. De hecho, y sin querer con esto forzar relación alguna entre ambas, la villa de cronología tardía mejor conocida, con existencia de una parte urbana con mosaicos, y que además cuenta con una torre de origen tardoantiguo, se encuentra a escasos seis kilómetros de Morosanto (PÉREZ AGUILAR, 1966). Aunque no debemos aferrarnos al origen aristocrático de este fenómeno, pues abandonos de villae y fundus para ser convertidos en centros productivos en manos de colonos se documentan en muchos lugares a partir del siglo $\vee$ d.C., si bien no pensamos que

\footnotetext{
12. La villa francesa de La Gramière (Castillon-du-Gard), cerca de Nimes, dedicada a la explotación vinícola, presenta ciertas similitudes en algunas de sus infraestructuras y planta, con la existencia de depósitos interconectados, conducciones abiertas y áreas de concentración del líquido resultante. En ella, además, la ausencia de dolia se achaca a la predilección (en necesidad, en parte) por los toneles de madera. (LEVEAU y BUFFAT, 2008: pp. I 55 y I56, fig).
} 
sea nuestro caso (ARCE, 2005: p. 240. WICKHAM, 2009: p. 760 y ss.) $)^{13}$.

El proceso de concentración de la propiedad que se documenta en muchas partes del imperio durante la Antigüedad Tardía, y que en el caso de Ronda va a suponer una reducción considerable de las instalaciones rurales detectadas sobre el terreno ${ }^{14}$, tendrá como una de sus consecuencias más reseñables la localización de los centros de producción en lugares distintos, y en ocasiones alejados, de los ocupados por el propietario, por el señor (CHAVARRÍA ARNAU, 200 I: p. 66) 15. En estos momentos la villa no se identifica con la pequeña o mediana explotación, principalmente agrícola, que contaba con casa de campo e instalaciones ligadas a las labores agropecuarias; la carga conceptual del término varía, aplicándose a una nueva realidad en la que cobra protagonismo la propiedad y no sólo la residencia. Propiedad, además, que no se circunscribe o relaciona exclusivamente con el lugar en donde reside su propietario, de tal manera que la villa quedará constituida por todas las tierras e instalaciones (posesiones) pertenecientes a un mismo terrateniente (possesor) (RIPOLL Y ARCE, 200I: p. 22. MARTíNEZ MELÓN, 2006: pp. ||3-131). Sin embargo, no conocemos lo suficientemente bien el asentamiento (en su completa extensión), como para afirmar de forma categórica que el dominus habitara en un lugar diferente.

En este sentido, en el que cobra una relevancia mayor el tratamiento y reformas que se ejecutan sobre la parte fructuaria de la villa con la intención de aumentar (o, simplemente, mantener) su producción, algunas de las dependencias o espacios originariamente vinculados a la zona habitable de la misma podrían haber sido objeto asimismo de un cambio en sus funciones, pasando a formar parte de la nueva configuración de la factoría como estancias de apoyo al proceso productivo. Tal vez esa sea la causa de que la natatio contara con la base para la colocación de un pilar central sobre el suelo de opus signinum, al que rompió, convirtiéndose finalmente, y aún con la instalación en funcionamiento, en un gran vertedero.

Pero de esta constatación no se debe concluir que Morosanto sea un ejemplo de villa aristocrática reconvertida en centro productivo, comparable a lo que se documenta en otros lugares del imperio occidental, pues no se puede re-convertir algo que ya venía funcionando como tal. Sí es cierto que la funcionalidad de algunos de los ambientes de la villa cambia, pero no tenemos lo suficientemente bien aislados los espacios domésticos privativos del aristócrata (la pars urbana), como para determinar que tales cambios supongan la amortización de su residencia. Tampoco se encuentran evidencias de que estas ampliaciones se hicieran a costa de espacios previamente "monumentalizados", enriquecidos, aunque también es verdad que esto depende mucho del estatus de su propietario ${ }^{16}$.

El destino de la producción seguiría siendo doble; el autoconsumo, que además debería satisfacer a una población dependiente aún

13. Mediados de esta misma centuria es la fecha que A. Chavarría propone como inicio del fin de la monumentalización de las villae aristocráticas, reflejo asimismo del colapso del sistema: (CHAVARRÍA ARNAU, 2006: p. 25).

14. Que de las II 5 datadas en época altoimperial (de las que sólo 77 tendrían una finalidad productiva claramente agrícola), pasan a la escasa veintena registrada para el Bajo Imperio (siendo su número aún menor para las villae más tardías que muestran características similares a las de Morosanto).

15. Acumulación de propiedades que hará que sus possesores, de alguna forma, diversifiquen los usos destinados a ellas, reservándose una de ellas, supuestamente, como lugar para su residencia. Sin embargo, este asunto se muestra para la autora bastante difuso, llegando a afirmar desconocer "dónde residían los propietarios de estas tierras cuando las uillae pierden su función residencial" (p. 66). La proximidad apuntada de otra importante villa en el mismo valle del Guadalcobacín, la de la Vizcondesa, que posee, además de una iglesia, de la que se excavó su posible baptisterio (PÉREZ AGUILAR, 1966), una torre aún en uso, y la cada vez más consolidada teoría de M. Acién sobre este tipo de elementos (ACIÉN ALMANSA, 2008), inicialmente ratificada sobre el terreno precisamente en nuestra zona, nos estimulan de manera especial para considerar esta última villa como la elegida por el señor para su asiento, y la torre como la nueva fórmula de concebir su residencia. E incluso, la de sus herederos inmediatos o parientes, pues no es la única torre conservada en el valle, ya que, más cercana a Morosanto, existe otra instalación de este tipo en el paraje conocido como La Hedionda. Sobre la presencia de edificios de culto en villae y la cronología de éstos (BROGIOLO y CHAVARRÍA, 2008: pp. 198 y 206).

16. Un resumen sobre el diferente comportamiento que presentan las villae ante las transformaciones, puede verse en RIPOLL y ARCE, 2001 : pp. 26 y ss. 
mayor (toda vez que las diferentes propiedades del señor no se dedicarían a transformar los mismos productos), y el comercio, casi con seguridad de carácter comarcal, pues no creemos que el interior participara de forma directa e intensiva en el mantenimiento de los flujos comerciales que, para estas fechas, se siguen dando en el Mediterráneo, aunque con este origen, todavía lleguen materiales a estas tierras ${ }^{17}$.

Fuera de toda esta discusión queda la necrópolis islámica que parece instalarse en la ladera del monte, por encima del castellum aquae. Su descubrimiento ciertamente nos ha desconcertado, pues habíamos abandonado por completo la posibilidad de existencia de restos de época medieval que apoyaran el origen del actual topónimo. De momento, no contamos con evidencias en el resto de la finca que permitan establecer algún tipo de relación, si bien es cierto que sabemos de la existencia de una pequeña guarnición militar apostada en el cerro trasero, llamado de Las Salinas, en el que se ubicaba una torre atalaya destruida por el Marqués de Cádiz en |48|, hoy totalmente desaparecida; y que muy cerca de aquí hay un lugar al que los paisanos de la zona llaman "el Convento", quién sabe si por referencia al "moro santo" que habitara por estos contornos.

\section{BIBLIOGRAFÍA}

ACIÉN ALMANSA, Manuel (2008): "Un posible origen de la torre residencial en al-Andalus", en Fars de I'Ilam. Antigues alimares d'al-Andalus. Primeres jornades cientifiques Ocorde, Barcelona, pp.57-88.

AGUAYO, Pedro; CASTAÑO, José Manuel y PADIAL, Bernardina (2004): "Análisis arqueológico de una manzana. Intervenciones de urgencia en el casco antiguo de Ronda, 1994-2000", Anuario Arqueológico de Andalucía, 200 I , t. III-2, Sevilla, pp. 772-788.
AMANTE SÁNCHEZ, Manuel y LECHUGA GALINDO, Manuel (|99|): "El yacimiento romano de 'Los Villaricos' (Mula, Murcia): Aproximación al estudio de una asentamiento rural de época romana en la Región de Murcia", Antigüedad y Cristianismo, 8, pp. 363-390.

ARCE, Javier (2005): Bárbaros y romanos en Hispania (400-507 A.D.), Madrid.

BROGIOLO, Gian Pietro. y CHAVARRÍA, Alexandra. (2008) "El final de las villas y las transformaciones del territorio rural en Occidente (siglos V-VIII)", en FERNÁNDEZ, C.; GARCÍA-ENTERO, V. y GIL, F. (eds.), Las villae tardorromanas en el occidente del Imperio. Arquitectura y función, Gijón, pp. 194-213.

CARRILERO MILLÁN, Manuel (1992): "El proceso de transformación de las sociedades indígenas de la periferia tartésica", en Actas del Seminario La colonización fenicia en el sur de la Península Ibérica. 100 años de investigación, Almería, pp. | |7-| 42.

CARRILERO MILLÁN, Manuel (2006): "Los Cilbicenos. Arunda y Acinipo, sus asentamientos en la Serranía de Ronda", en Memorias de Ronda. Revista de historia y estudios rondeños, 3, pp. 62-77.

CARRILERO, Manuel et Alii (GARRIDO, Olga; NIETO Bartolomé y PADIAL, Bernardina)( 1995):"La villa romana de Las Viñas (Cuevas del Becerro, Málaga) y el poblamiento rural romano en la Depresión de Ronda", Florentia lliberritana, 6, pp. 89-108.

CARRILLO DÍAZ-PINÉS, José Ramón ( 1995): "Dispositivos para la producción de aceite en época romana en Andalucía", en Atti dell'XI Convengo di Studio Cartegine. 15-18 dicembre 1994,Túnez, pp. 6 | I-627 (esp. 615).

CASTAÑO, José Manuel y NIETO, Bartolomé (coord.) (2009): La ciudad romana de Acinipo. Investigaciones 2005 2007. Avance de resultados, en Cuadernos de Arqueología de Ronda, 3.

CHAVARRÍA ARNAU, Alexandra (200 I): "Poblamiento rural en el territorio de Tarraco durante la antigüedad tardía", Arqueología y Territorio Medieval, 8, pp.55-76.

CHAVARRÍA ARNAU, Alexandra (2006): "Villas en Hispania durante la Antigüedad tardía", en CHAVARRÍA, Alexandra; ARCE, Javier y BROGIOLO, G.P.; Villas tardoantiguas en el Mediterráneo Occidental, Anejos de Aespa, XXXIX, Madrid, pp. 17-35.

FORNELL MUÑOZ, Alejandro (2005): Las villae romanas en la Andalucía mediterránea y del Estrecho, Jaén.

LAGÓSTENA BARRIOS, Lorenzo G. y MATA ALMONTE, Esperanza (2007): "Oleicultura romana en la cuenca del Guadalete: la almazara de Fuente Grande, Alcalá delValle", en I Congreso de Cultura del Olivo, Jaén, pp. I57-I76.

\footnotetext{
17. En este sentido, la regionalización del comercio puede ponerse directamente en relación con la nueva estructura de la propiedad aludida más arriba, y con unas nuevas formas de explotación adaptadas a esa, también novedosa, realidad: realidad en la que debió tener mucho que ver la desarticulación de la administración romana y la generación de los primeros reinos bárbaros (CHAVARRÍA ARNAU, 2006: p. 34).
} 
LEVEAU, Philippe y BUFFAT, Loïc (2008) "Les bâtiments agricoles et l'architecture des villas de la fin de l'Antiquité", en FERNÁNDEZ, C.; GARCÍA-ENTERO,V.y GIL, F. (eds.), Las villae tardorromanas en el occidente del Imperio. Arquitectura y función, Gijón, pp. I 55 y 156.

MADOZ, Pascual ( 1986): Diccionario geográfico-estadísticohistórico de España y sus posesiones de ultramar, Madrid (I 845- | 850), edición facsímil, Salamanca.

MARTÍNEZ MELÓN, José Ignacio (2006): "El vocabulario de los asentamientos rurales (siglos I-IX d. C.): Evolución de la terminología", en CHAVARRÍA, Alexandra; ARCE, Javier y BROGIOLO, G.P.; Villas tardoantiguas en el Mediterráneo Occidental, Anejos de Aespa, XXXIX, Madrid, pp. ||3-|3|.

MORA SERRANO, Bartolomé (1987-88): "Reacuñaciones en la ceca de Acinipo", Acta Numismática, 17-18, pp. 89-100.

MORA SERRANO, Bartolomé (1990): "Malaca, Acinipo y Lacipo: tres cecas monetales en los territorios malacitanos", Jábega, 67, pp. 3-12.

MORA SERRANO, Bartolomé (2000):"Acinipo", en RIPOLLÉS, P.P. y ABASCAL, J.M.: Monedas hispánicas. Catálogo del Gabinete de Antigüedades de la Real Academia de la Historia, Madrid, pp. I0I-103.

NIETO GONZÁLEZ, Bartolomé (1994): "El proceso histórico de Arunda y su territorio circundante durante la fase cultural romana", en Recuerdos de Ronda y su Historia (II), Ronda, pp. 214-242.
PERDIGUERO, Manuel (1996): "La fase romana de Arastipi (Cauche el Viejo, Antequera). El molino de Aceite", Mainake, XVII-XVIII, pp. I25-I69.

PÉREZ AGUILAR, Alfonso (1966): “¿Una basilica paleocristiana en Ronda (Málaga)?, en IX Congreso Nacional de Arqueología (Valladolid, 1965), Zaragoza, pp. 397-404.

RIPOLL, Gisela y ARCE, Javier (200 I): "Transformación y final de las villae en Occidente (siglos IV-VIII): problemas y perspectivas", Arqueología y Territorio Medieval, 8 , pp.21-54.

RODRÍGUEZ MARTÍNEZ, Francisco ( 1977$)$ : La Serranía de Ronda. Estudio geográfico, Málaga.

ROMERO, Manuel (1993): "El Gallumbar, una villa dedicada a la producción de aceite", Anuario Arqueológico de Andalucía/ / 987, t. III, Sevilla, pp. 500-508.

ROMERO, Manuel (1998): "Algunas reflexiones sobre la producción de aceite en las villas de la comarca de Antequera", Mainake, XIX-XX, pp. I I5-I4I.

UROZ SÁEZ, José (1999): "La agricultura ibérica del Levante en su contexto mediterráneo", Studia Historica. Historia Antigua, 17, pp. 59-85

VV.AA. (1994): La Serranía de Ronda, Madrid.

WICKHAM, Chris (2009): Una historia nueva de la Alta Edad Media. Europa y el mundo mediterráneo, 400-800, Barcelona. 


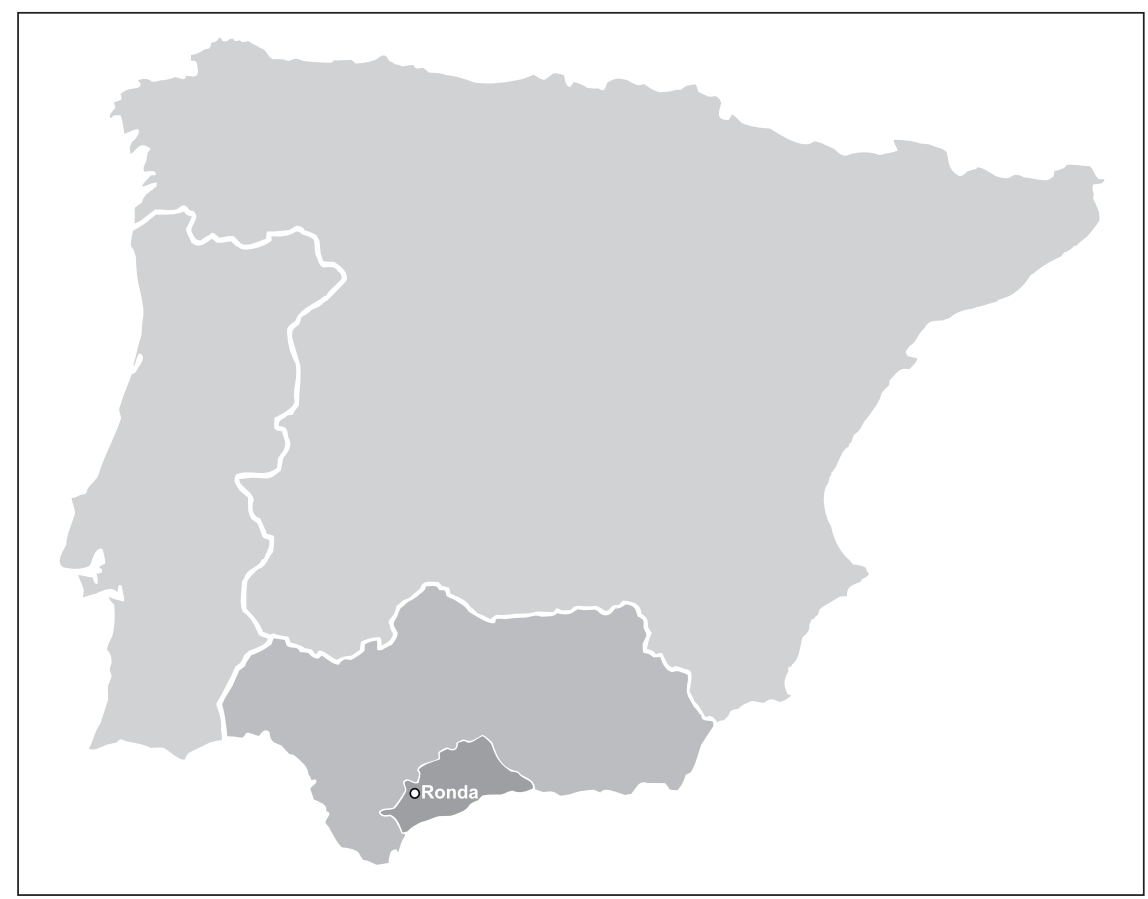

Fig. I. Situación de Ronda

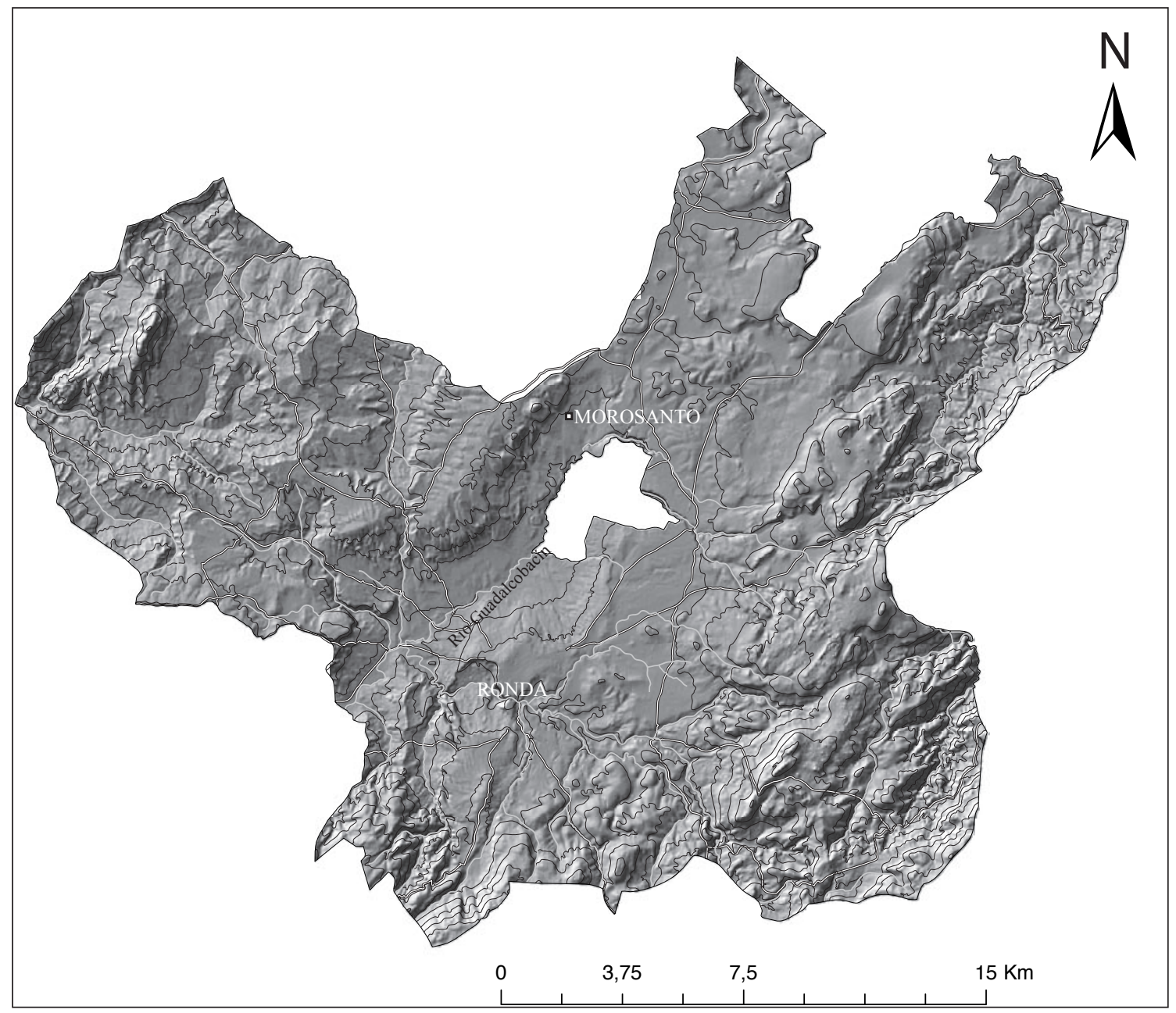

Fig. 2. El término municipal de Ronda 


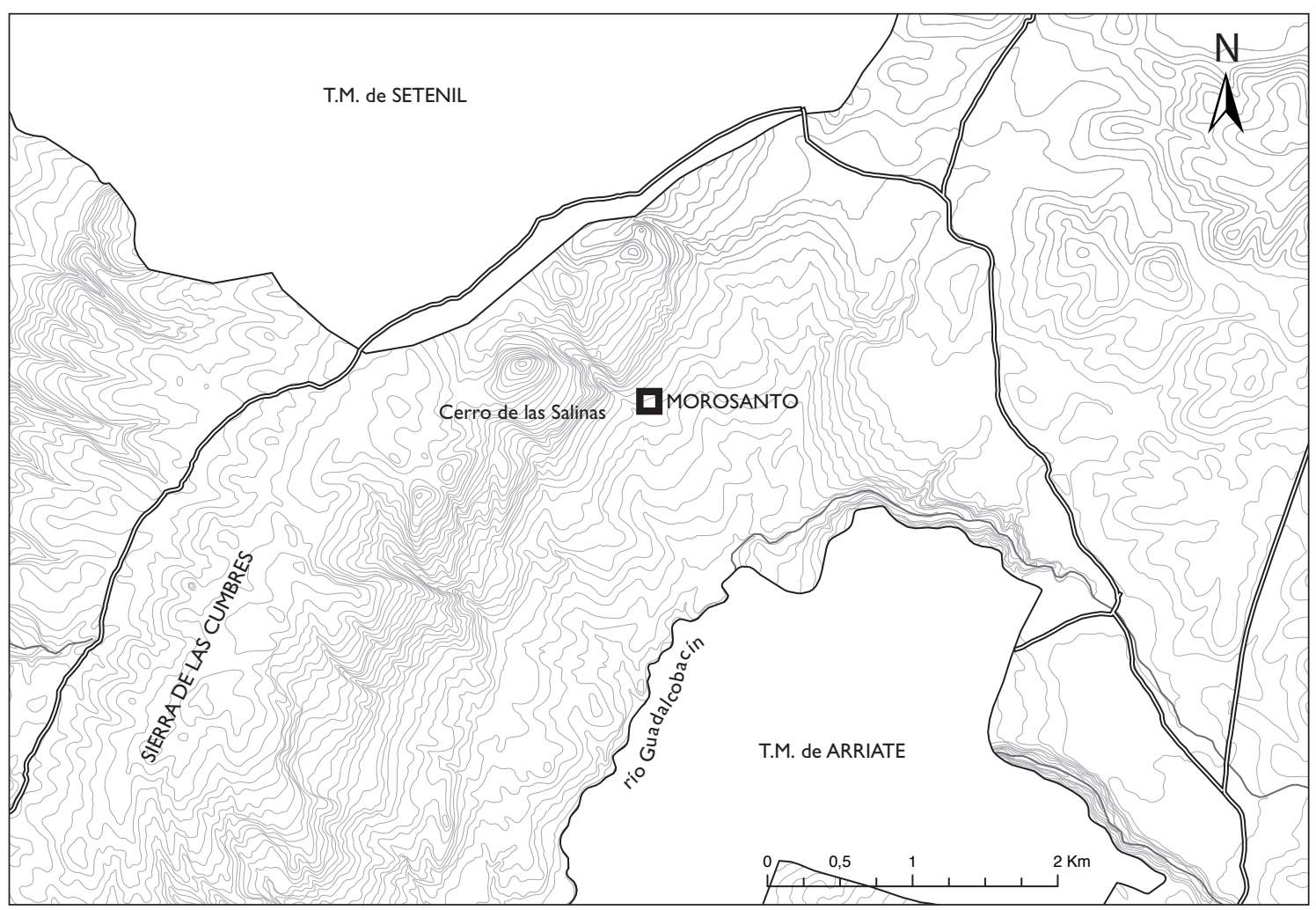

Fig. 3. Situación del yacimiento de "Morosanto"

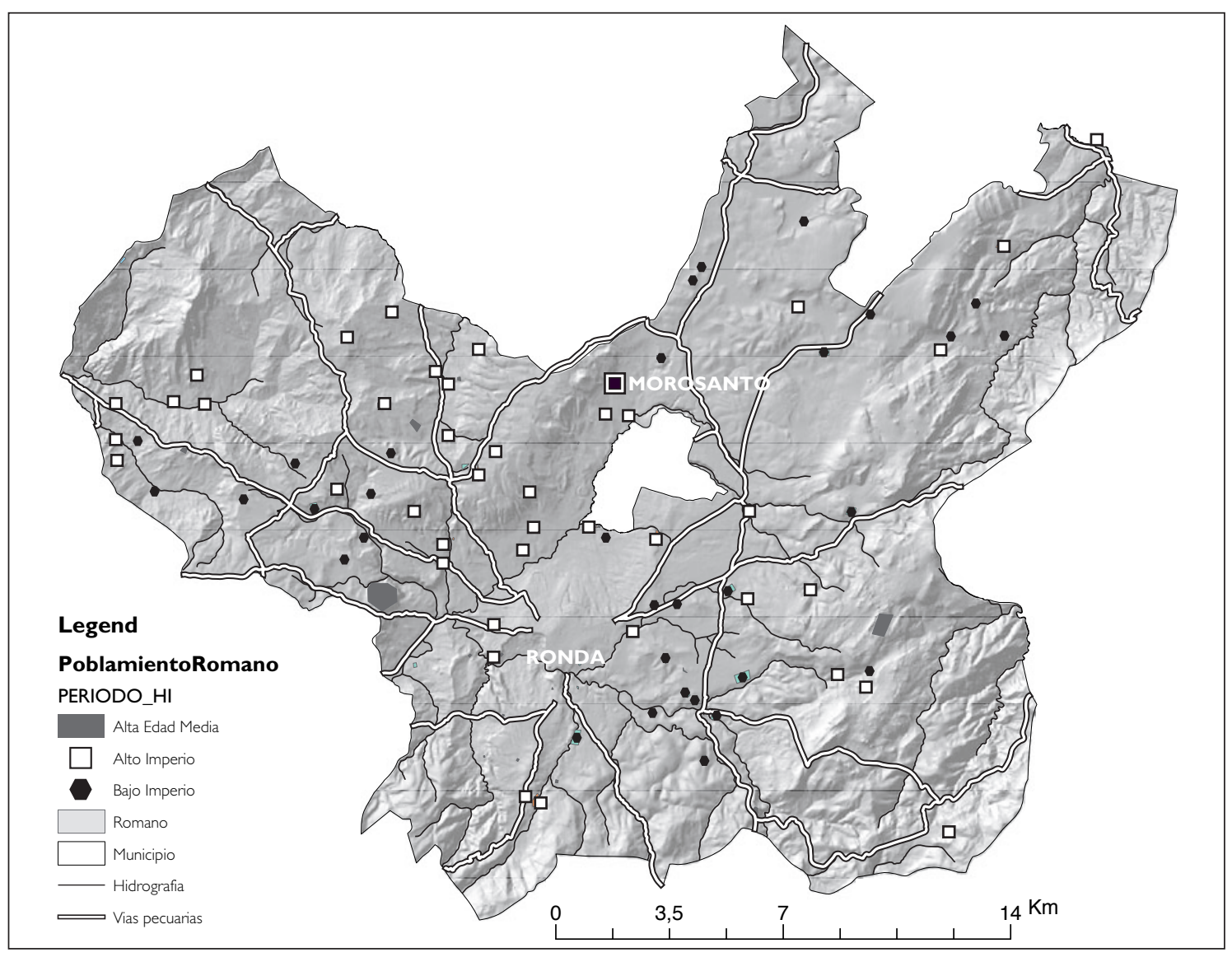

Fig. 4. El poblamiento romano en el T.M. de Ronda 


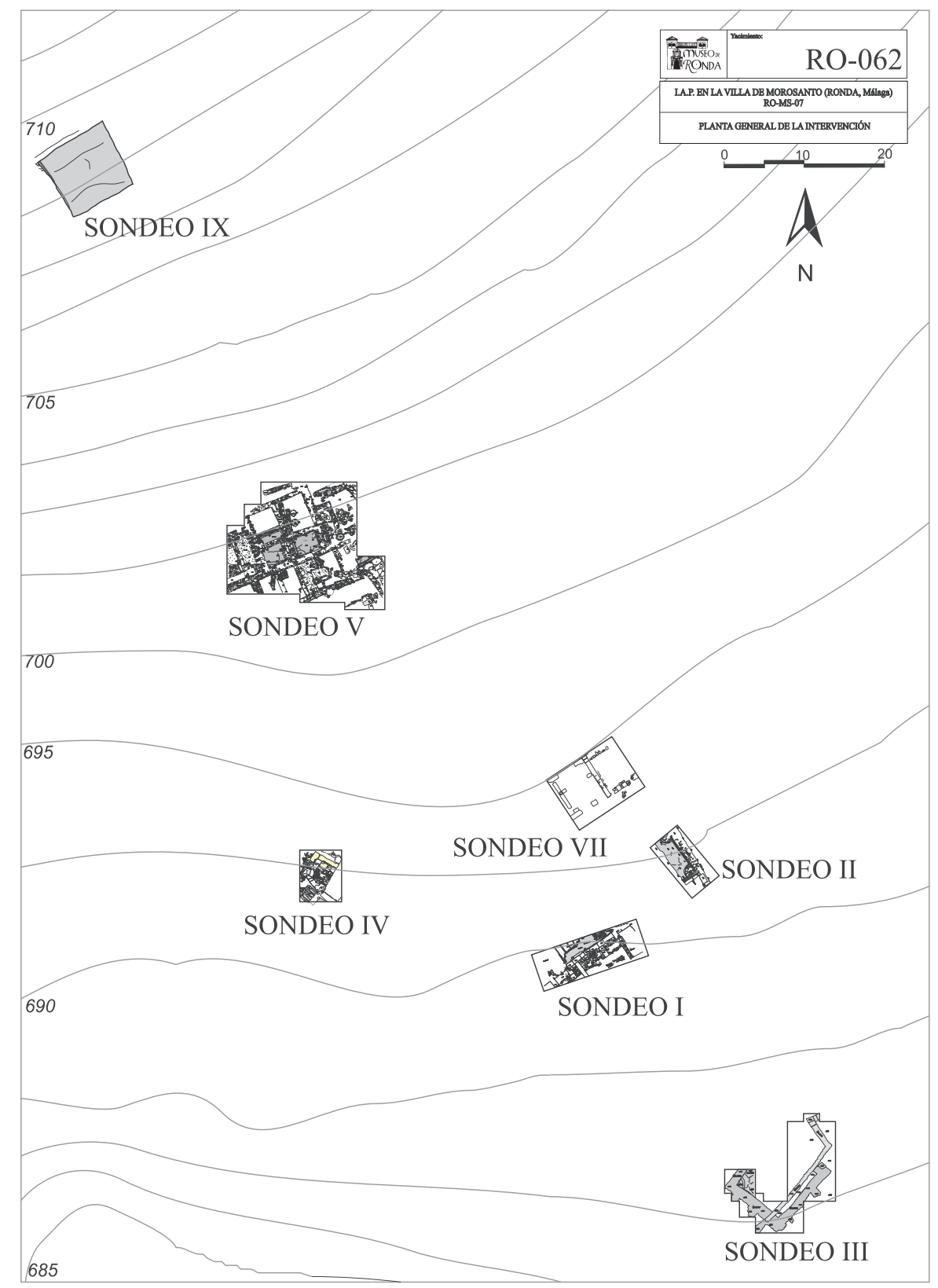

Fig. 5. Situación de los sondeos referidos en el texto

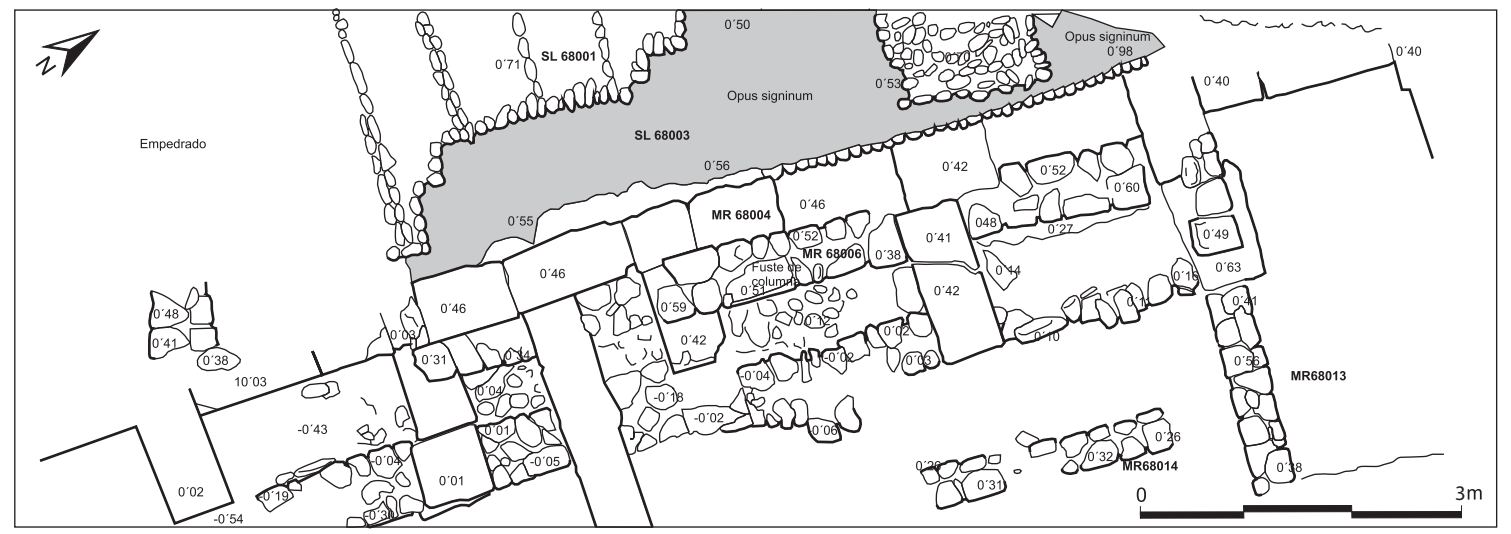

Fig. 6. Planta final del Sondeo I 


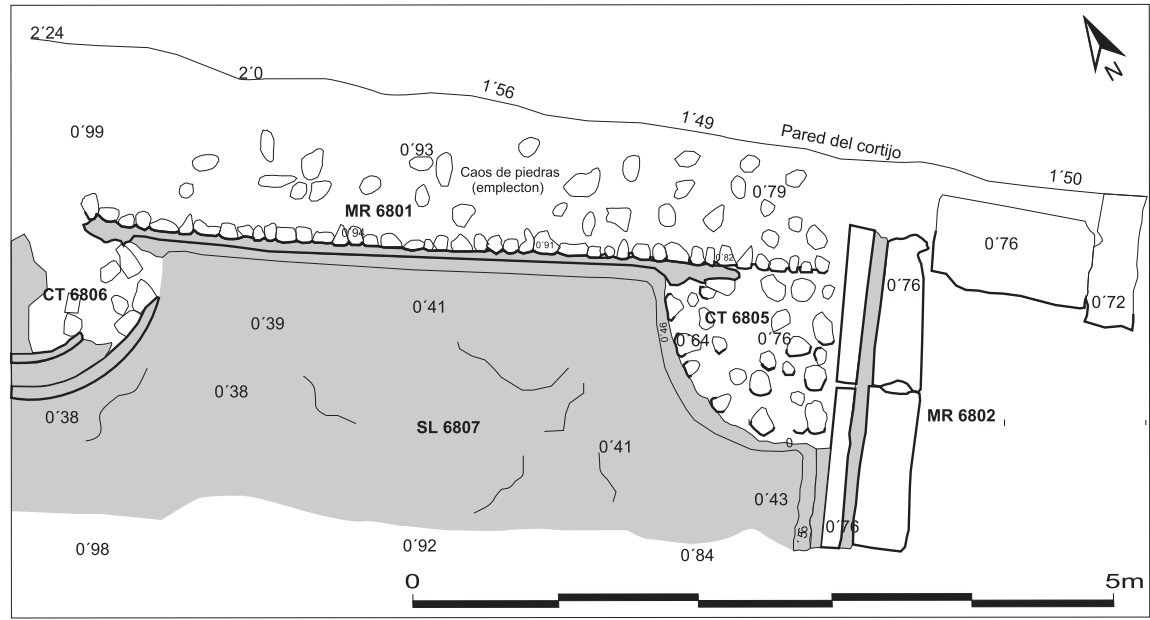

Fig. 7. Planta final del Sondeo II

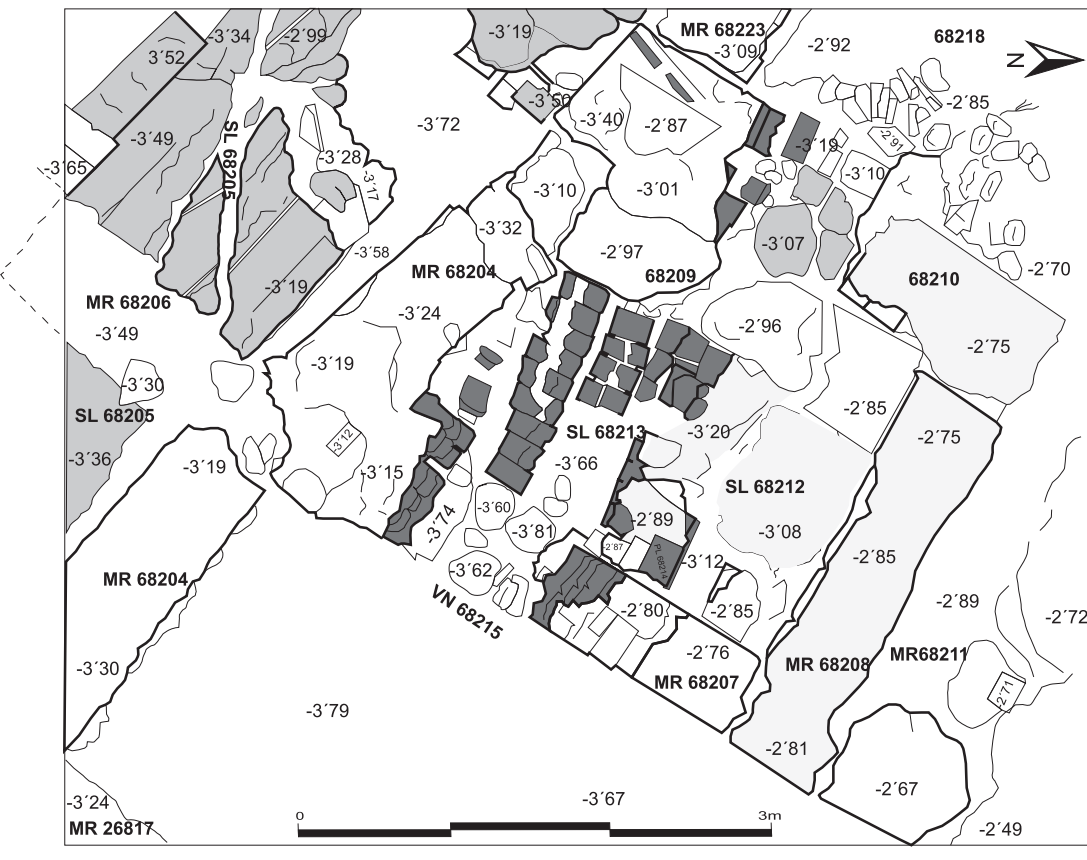

Fig. 8. Planta final del Sondeo IV

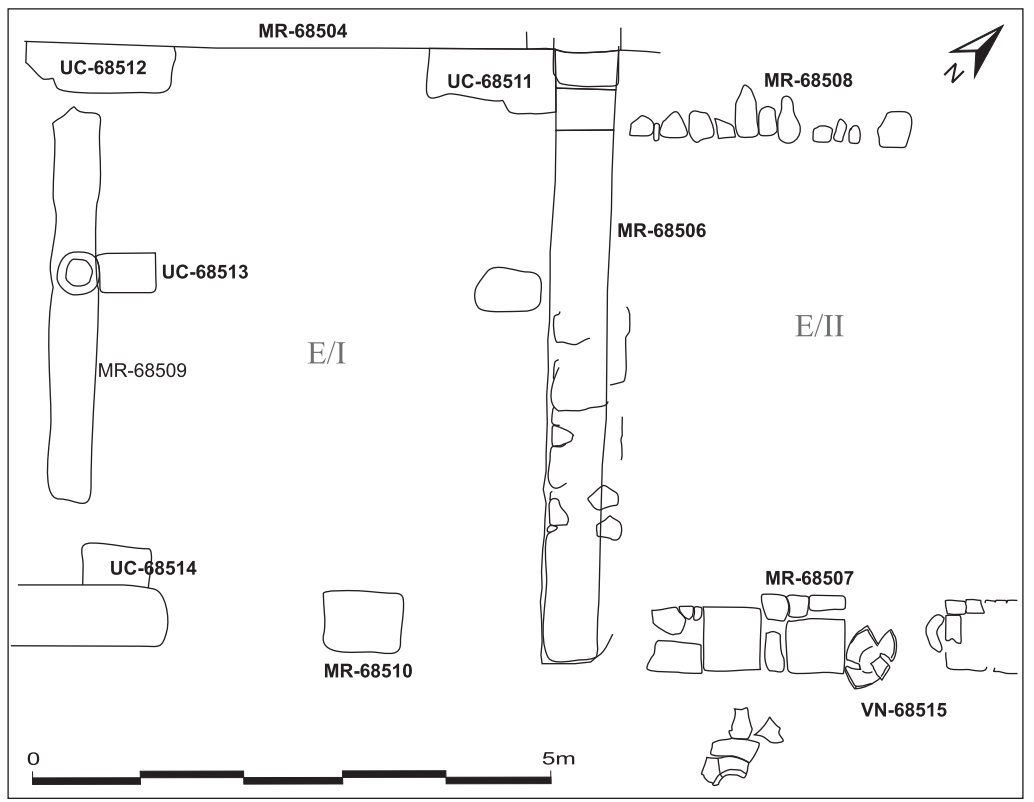

Fig. 9. Planta final Sondeo VII 


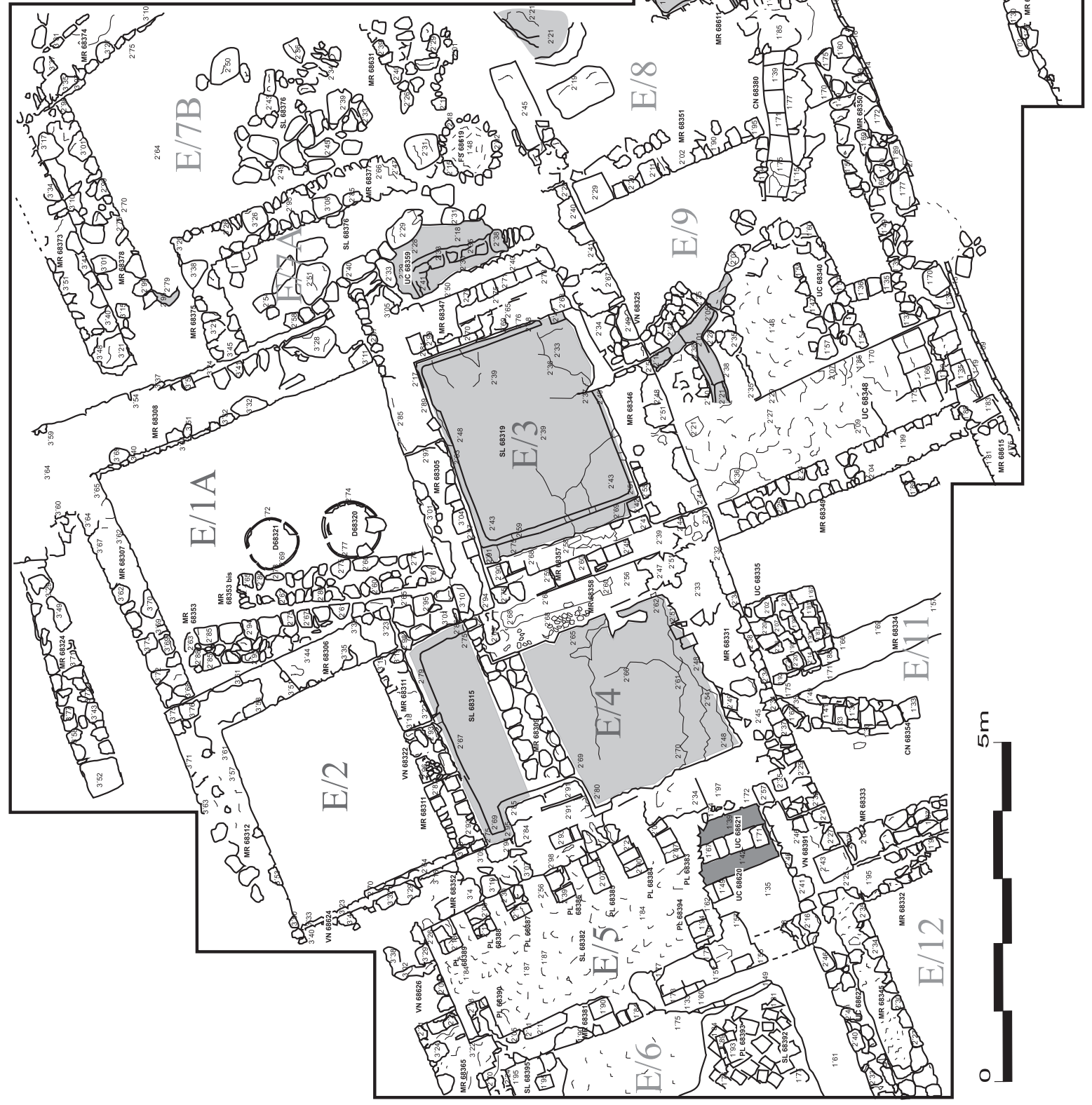




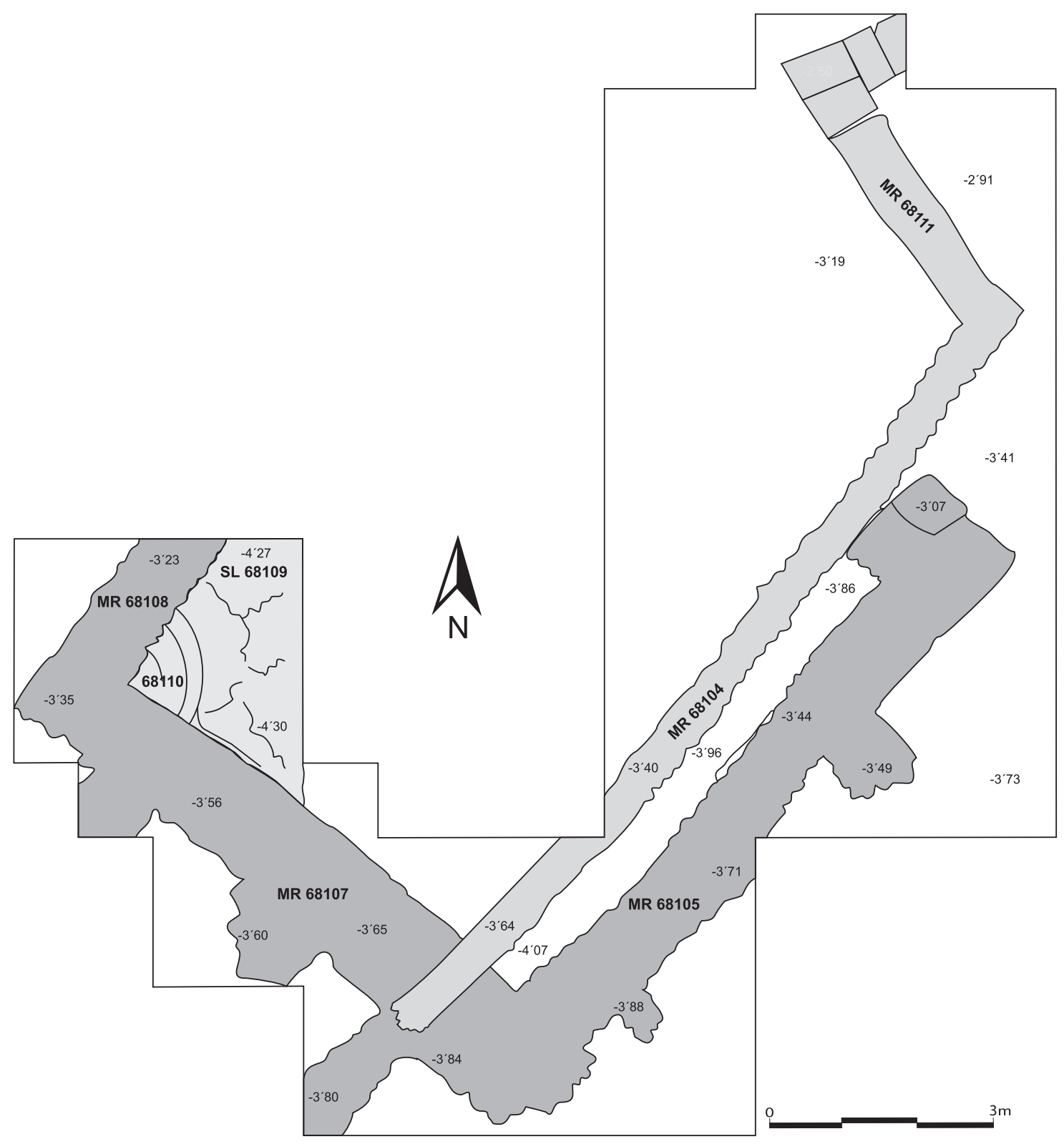

Fig. II. Planta final del Sondeo III 


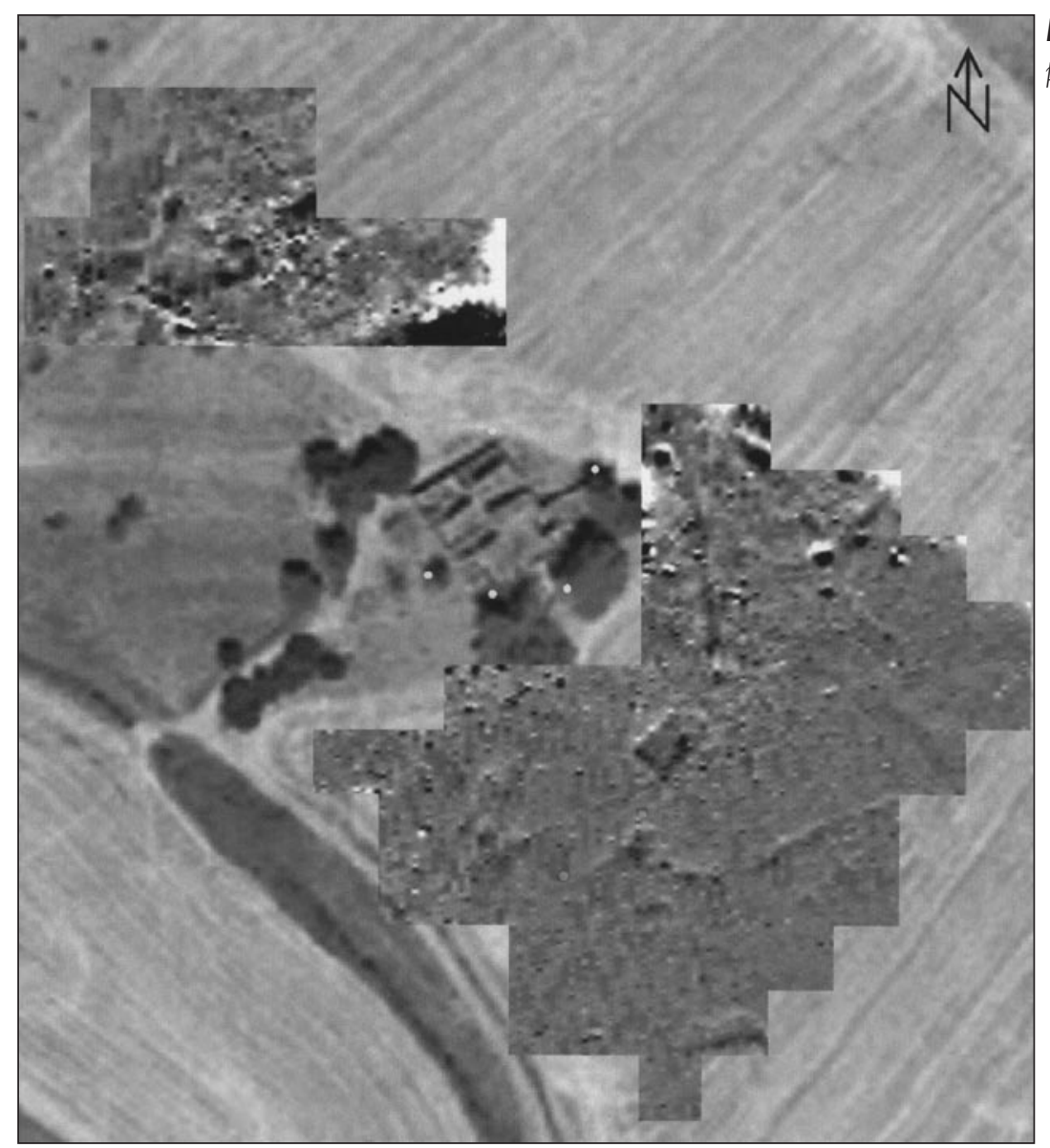

Lám. I. Área de

prospección geofísica

Lám. II. Muro de natatio divisorio entre terrazas

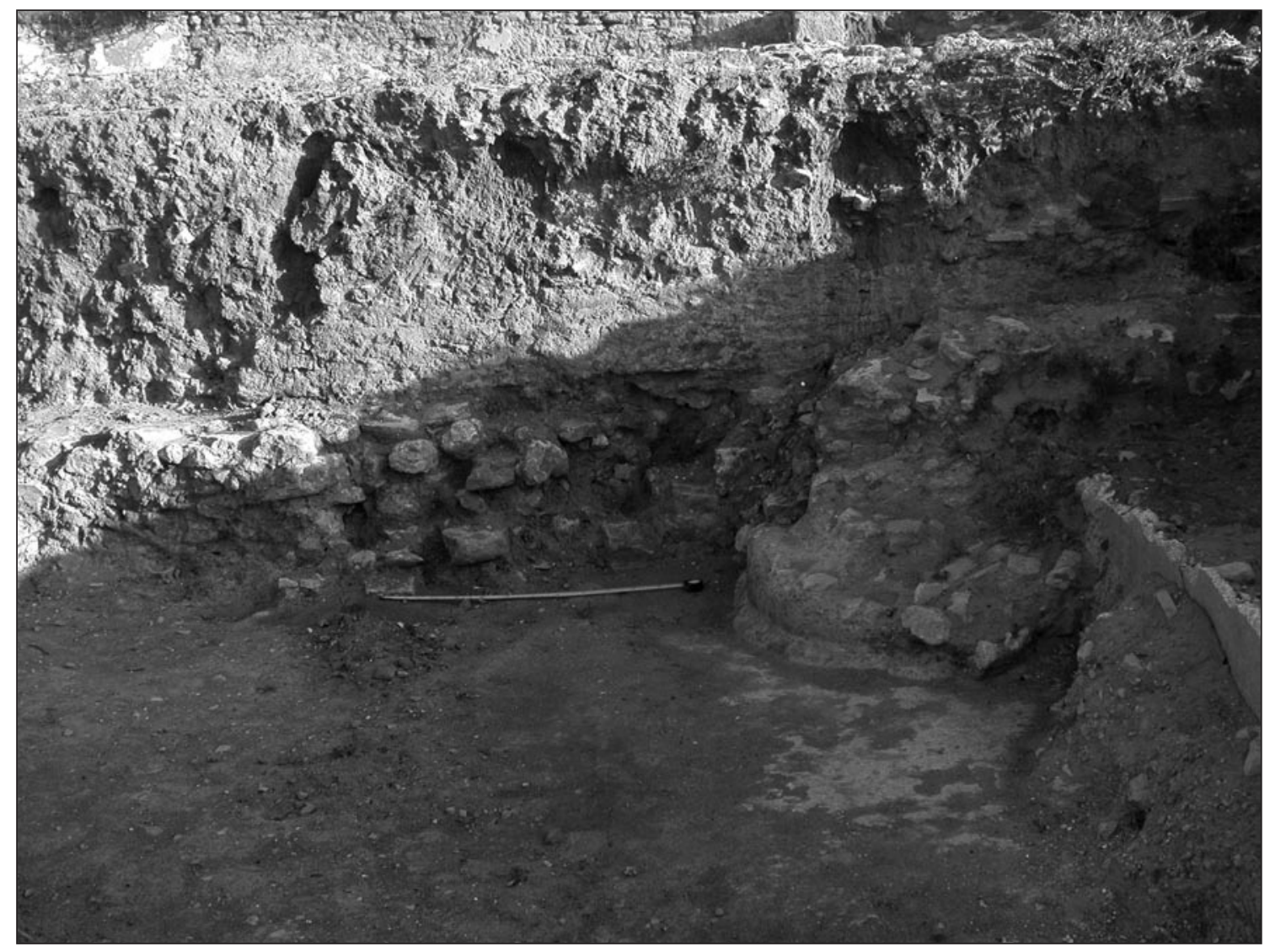




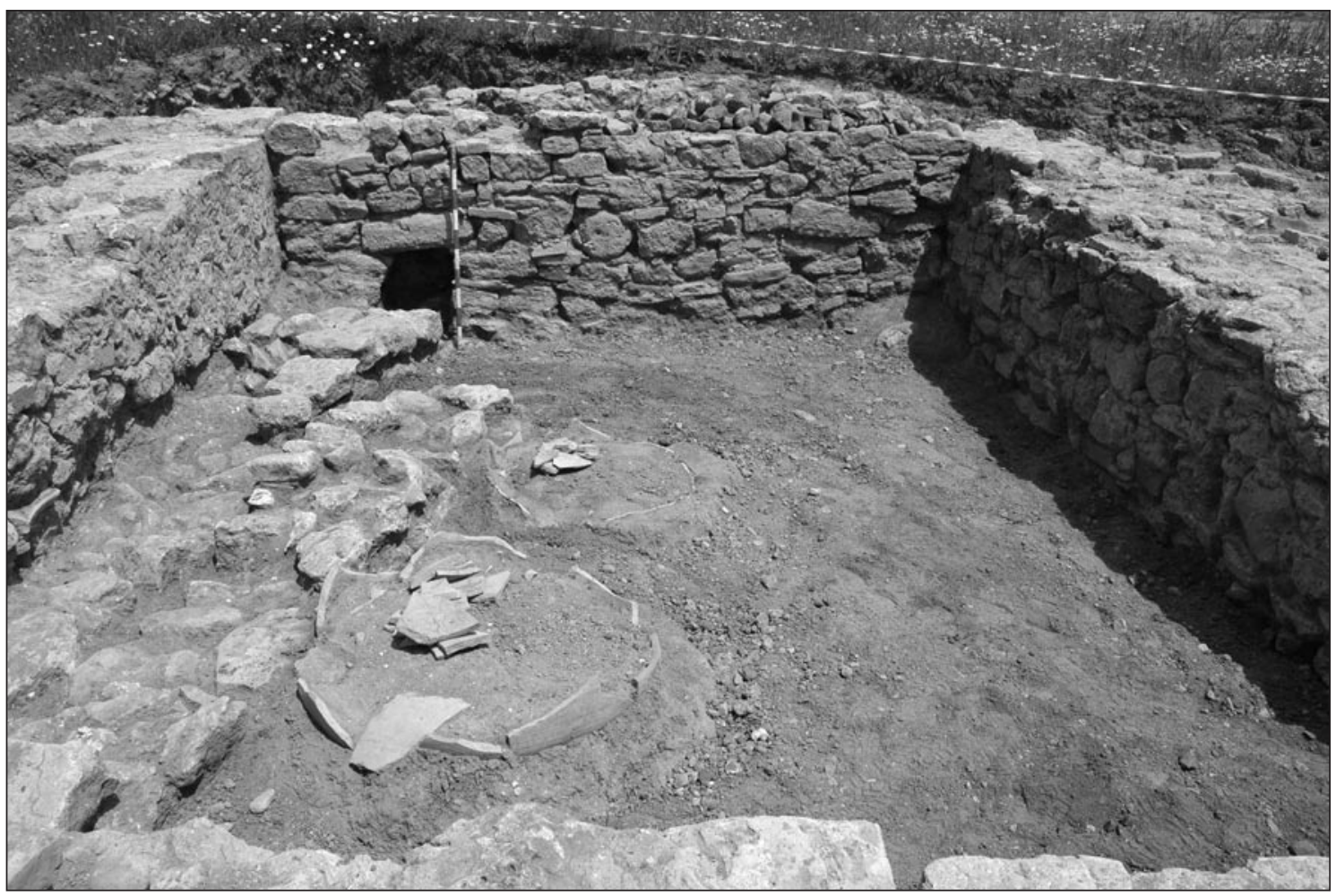

Lám. III. Vista general de la Estancia I

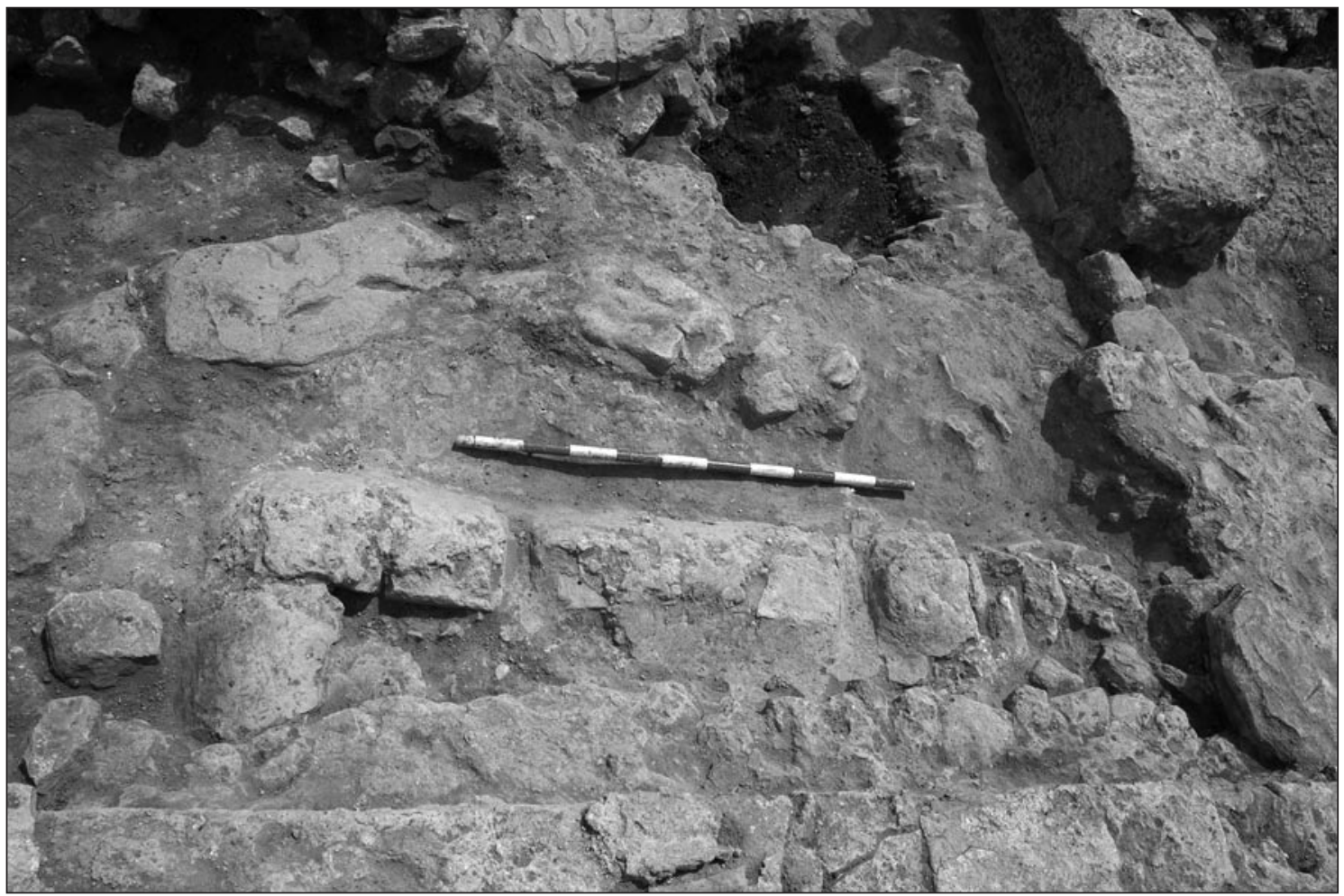

Lám. IV. Posible ara de opus signinum 


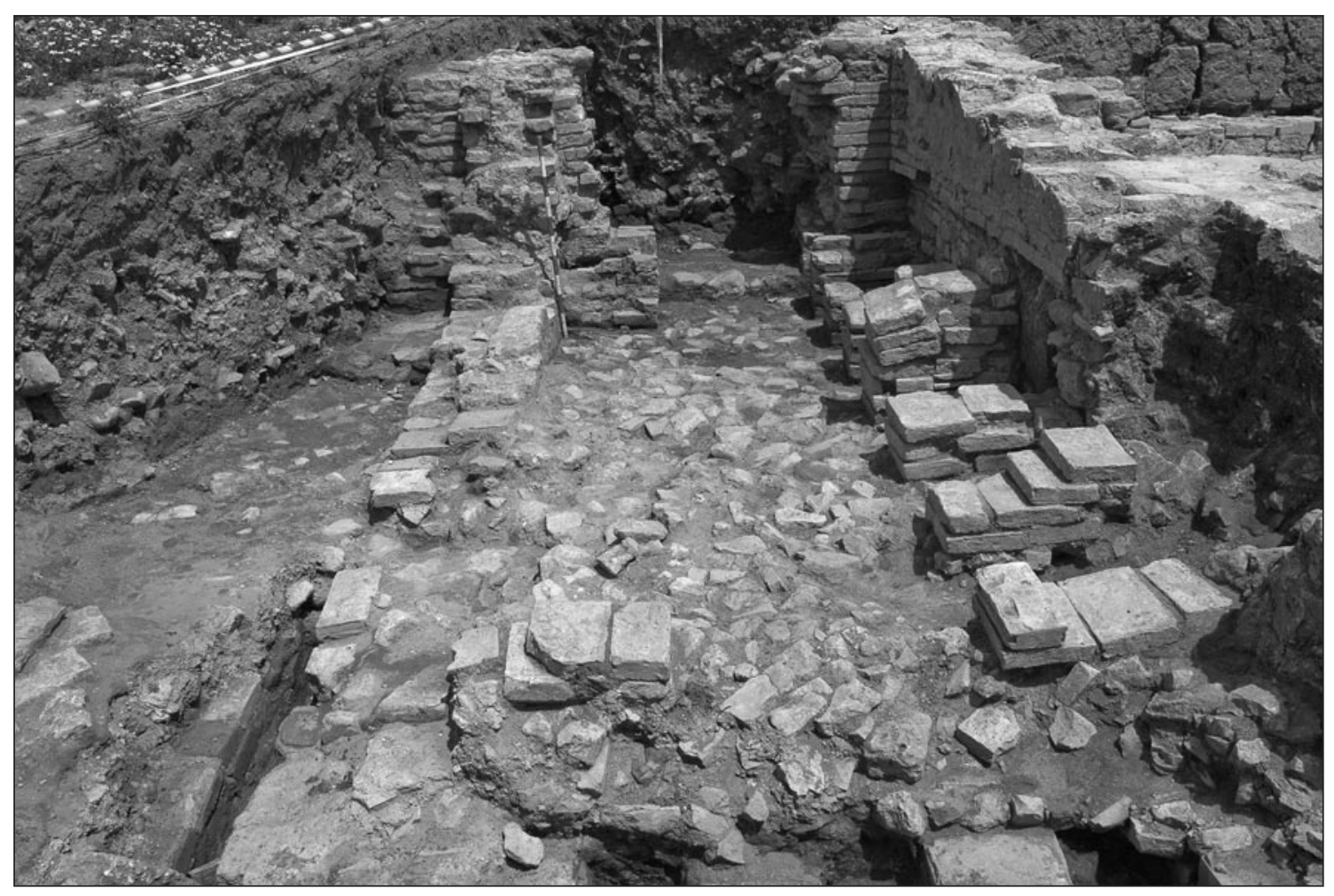

Lám. V. Hipocausto 